\title{
A Self-Limiting Bank Erosion Mechanism? Inferring Temporal Variations in Bank Form and Skin Drag from High Resolution Topographic Data
}

Julian Leyland $^{1}$, Stephen E. Darby ${ }^{1}$, Liliana Teruggi ${ }^{2}$, Massimo Rinaldi ${ }^{2}$, Daniele Ostuni ${ }^{3}$

1 Geography and Environment, University of Southampton, UK, SO17 1BJ

2 Department of Earth Sciences, University of Florence, Italy

3 Department of Civil and Environmental Engineering, University of Florence, Italy
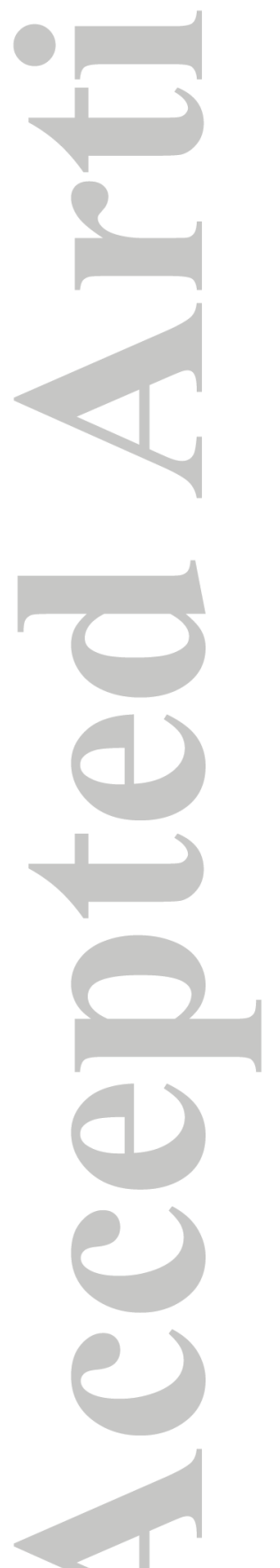

This article has been accepted for publication and undergone full peer review but has not been through the copyediting, typesetting, pagination and proofreading process, which may lead to differences between this version and the Version of Record. Please cite this article as doi: 10.1002/esp.3739 


\section{Abstract}

Fluvial bank erosion rates are often quantified by assuming that the erosion rate is a function of the excess (above a critical threshold) boundary shear stress applied by the flow. Research has shown that the form roughness induced by natural topographic bank features, such as slumps, spurs and embayments, is the dominant component of the spatially-averaged total shear stress, meaning that form roughness provides an important control on bank erosion rates. However, measuring the relative components of the total shear stress for a natural system is not straightforward. In this paper we employ the method of Kean and Smith (2006a,b) to partition the form and skin drag components of river bank roughness using a time series (2005-2011) of high-resolution topographic surveys of an eroding bank of the Cecina River in central Italy. This method approximates the form drag component of the roughness along a longitudinal bank profile as a series of user defined Gaussian curves. The extracted metrics are used in conjunction with an estimate of the outer region flow velocity to partition the form and skin drag components of the total boundary shear stress according to the Kean and Smith analytical solution. The relative magnitude of the form and skin shear stress at each survey date is analysed alongside DEMs of difference to reveal that intense episodes of erosion are followed by periods of quiescence. We show that this is due to the protection offered by increased form drag roughness following erosion. We conceptualise the dynamic feedbacks that exist between river discharge, bank erosion processes and bank form roughness, into a simple model of the self-limiting nature of river bank erosion.

\section{Key Words}

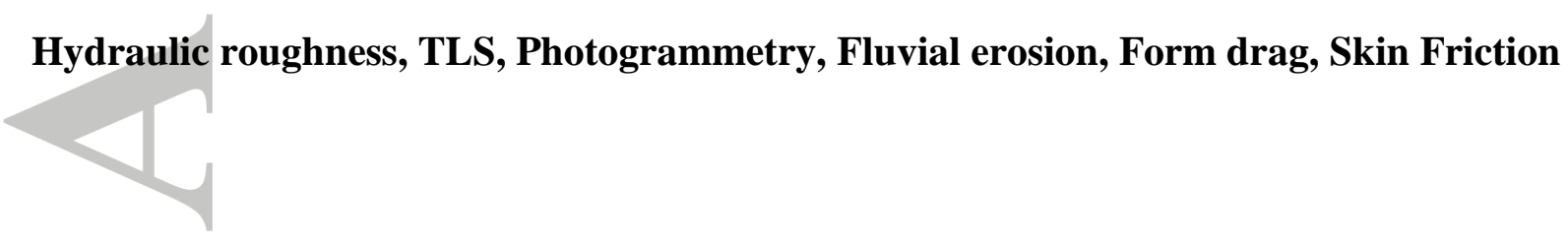




\section{INTRODUCTION}

Bank erosion is a key process in fluvial dynamics, with significant fractions of the total sediment load being sourced from river banks (Rinaldi and Darby, 2008). The sediment supplied from bank erosion aids in the establishment of river and floodplain morphology and their associated habitats (Thorne and Lewin, 1979; Millar, 2000; Goodson et al., 2002; Eaton et al., 2004), while simultaneously contributing to losses of channel conveyance (Piégay et al., 2005) and nutrient or contaminant problems downstream (e.g., Marron, 1992; Reneau et al., 2004; O’Neal and Pizzuto, 2011). When rivers flow through densely populated regions, even modest rates of bank erosion can present a significant hazard to built infrastructure. For these reasons knowledge of the rates, patterns and controls on bank erosion events that release sediment to river systems is fundamentally important in understanding fluvial sediment transport regimes, and in underpinning the sustainable management of fluvial environments and their dependent habitats.

Unfortunately, predicting rates of bank erosion is a challenging problem, not least because bank retreat reflects the net contribution of three separate, but interacting, groups of processes: weathering, fluvial (hydraulic) erosion, and mass-wasting under gravity. Previous authors (e.g., Lawler, 1992; Rinaldi and Darby, 2008) have argued that in the middle to lower portions of most drainage basins, bank retreat is usually dominated by a combination of hydraulic erosion and mass failure. Such conceptualisations do not exclude the importance of weathering, but rather they view the role of weathering processes as mainly inducing temporal variations in bank material erodibility (Prosser et al., 2000, Couper and Maddock, 2001; Lawler, 2004; 2005), such that their effect can be accounted for implicitly within fluvial erosion models. It may also be noted that mass-wasting is often triggered by fluvial erosion steepening or undercutting the bank profile to the point of failure (Thorne, 1982; 
Darby et al., 2007; Rinaldi and Darby, 2008). Moreover, the concept of basal endpoint control indicates that, once mass - failure has delivered sediment to the basal region, evacuation of that material by fluvial erosion is necessary if mass-wasting is to continue to contribute to bank retreat (Carson and Kirkby, 1972; Thorne, 1982; Rinaldi and Darby, 2008). For all these reasons the rate of hydraulic erosion at the toe of the bank can reasonably be considered to be the dominant factor controlling bank retreat (Thorne, 1982; Rinaldi and Darby, 2008), particularly when considering longer term $\left(>\sim 10^{1}\right.$ bank erosion event episodes) rates of bank retreat (Darby et al., 2010). Yet, in contrast to the large numbers of recent bank erosion studies that have focused on mass-wasting, there have been comparatively few studies of fluvial erosion (see Rinaldi and Darby, 2008).

Rates of hydraulic bank erosion are most commonly quantified using an excess shear stress formula such as (Partheniades, 1965; Arulanandan et al., 1980):

$$
\varepsilon=k\left(\tau_{S F}-\tau_{c}\right)^{a}
$$

where $\varepsilon(\mathrm{m} / \mathrm{s})$ is the fluvial bank erosion rate per unit time and unit bank area, $\tau_{s f}(\mathrm{~Pa})$ is the skin drag component of boundary shear stress (see below), $k\left(\mathrm{~m}^{2} \mathrm{~s} / \mathrm{kg}\right)$ and $\tau_{c}(\mathrm{~Pa})$ are erodibility parameters (coefficient, $k$, and critical shear stress, $\tau_{c}$ ) and $a$ (dimensionless) is an empirically-derived exponent, often assumed to take a value of 1 in bank erosion studies (Rinaldi and Darby, 2008). When applying equation (1) to studies of hydraulic bank erosion, it is necessary to partition the boundary shear stress into the skin drag and form drag components, the former being the stress available for bank erosion (as noted in the definition of terms above). Those few empirical and numerical studies that have investigated near bank flows confirm that the form drag component, which arises from wakes shed by the irregular 
topography (protrusions) characteristic of eroding river banks, is normally dominant (Thorne and Furbish, 1995; McBride et al., 2007; Darby et al., 2010). This means that failure to accurately parameterise the form drag component can lead to errors in predictions of erosion rate (Darby et al., 1998; Mosselman, 1998; Julian and Torres, 2006), but the complexity of the wake-shedding process has, until recently, inhibited analytical solutions.

One promising approach to the partitioning of skin and form drag on eroding river banks is the model proposed by Kean and Smith (2006a,b) (see Section 3.3 for full details). For example, Darby et al. (2010) and Nardi et al. (2013) have employed the Kean and Smith model, in conjunction with direct field measurements of the parameters $k$ and $\tau_{c}$, to develop predictions of fluvial bank erosion rate using equation (1). However, a number of limitations still remain. Of particular significance to the present study is the assumption that the skin and, particularly, form drag components of bank roughness remain time-invariant throughout the erosion process. Clearly, the process of bank erosion (or deposition) must lead to adjustments of the local (meaning, at a cross-section) geometrical attributes of the riverbank, which in turn may affect the partitioning of roughness. In section 3.5 we provide an overview of the means by which specific bank morphological properties can be used to estimate the form and skin drag components of river bank roughness using the Kean and Smith $(2006 a, b)$ model. However, suffice to state here that the Kean and Smith (2006a,b) model is based on downstream variations in flow-bank morphology interactions, with a particular emphasis on evaluating how wakes shed by local bank protrusions affect the near-bank flow field and roughness immediately downstream. That is, Kean and Smith $(2006 a, b)$ treat the skin and form drag components of bank roughness as reach-averaged values that account for streamwise variability in the morphology of numerous bank protrusions. Consequently it is unclear whether local adjustments in bank morphology under erosion lead to situations where 
the reach-averaged bank roughness remains time-invariant or not. Furthermore, in the case of the latter it is not known if temporal variations in bank roughness under erosion are either (i) non-systematic or (ii) involve a mutual feedback between roughness and erosion, as might be suggested by analogy with studies that have investigated the mutual interactions between flow and bedforms (Smith and Mclean, 1977; Nelson and Smith, 1989; Bennett and Best 1996).

\section{AIMS \& OBJECTIVES}

Recent adyances in topographic data collection techniques such as digital photogrammetry (e.g., Lawler, 1993; Barker et al., 1997; Pyle et al., 1997) and terrestrial laser scanning (TLS; e.g., Milan et al., 2007; Alho et al., 2009; Resop and Hession, 2010) mean that the opportunity now exists to collect sufficiently high resolution data to resolve the relevant scales of roughness necessary to define the skin and form drag components of eroding river banks. While some studies have used TLS techniques to provide insights into the detailed nature of river bank erosion and/or deposition processes (e.g. Alho et al., 2009; Pizzuto et al., 2010; O'Neal and Pizzuto, 2011), none as yet have exploited their potential to address the specific question of how the two components of bank roughness (form and skin drag) evolve during the bank erosion process. The aim of this paper is to analyse temporal sequences of high-resolution bank topographic data sets to quantify variations in the skin and form drag components of bank roughness on an actively eroding bank. The specific objectives are as follows:

1. To generate a set of contiguous, spatially referenced, high resolution Digital Elevation Models (DEMs) and DEMs of Difference (DoDs) for a deeply incised river bank on the Cecina River, Italy. 
2. Extract a time series of metrics to characterise the local form and skin drag components of the bank roughness.

3. In conjunction with hydrological data use the information from 2 to explore how flows might interact with the changing bank forms and roughness parameters to induce variable cycles of erosion.

\section{METHODS}

\subsection{Study Site Description}

Located in Tuscany (central Italy), the Cecina River $\left(905 \mathrm{~km}^{2}\right)$ flows into the Tyrrhenian Sea roughly $50 \mathrm{~km}$ south of Pisa (Figure 1A). Located within the Mediterranean zone, the Cecina experiences a temperate climate with a dry season (mean annual precipitation of $944 \mathrm{~mm}$ ), such that the river exhibits high variability in flow discharges. The Cecina has been the focus of a number of studies concerned with various aspects of bank erosion (Rinaldi et al., 2008; Luppi et al., 2009) and channel morphodynamics (Bartholdy and Billi, 2002; Benvenuti et al. 2008; Teruggi and Rinaldi, 2009), and a range of data pertinent to this study are, therefore, readily available (see below). We investigate the same study reach as employed in the studies of Rinaldi et al. (2008), Luppi et al. (2009) and Teruggi et al. (2011), which is located within the middle-lower portion of the basin, at the confluence of the Sterza River, $20 \mathrm{~km}$ from the outlet and $2 \mathrm{~km}$ downstream of the main flow gauging station for the catchment (Ponte di Monterufoli; drainage area $634 \mathrm{~km}^{2}$ ) (Figure 1A). The mean daily discharge as measured at this gauging station is $7.61 \mathrm{~m}^{3} / \mathrm{s}$, while the peak discharge with a 2 -year return period $\left(Q_{2}\right)$ is $322 \mathrm{~m}^{3} / \mathrm{s}$. The study site is about $500 \mathrm{~m}$ long, including an actively eroding (left) bank $(\sim 2.7$ $\mathrm{m} / \mathrm{yr}$; Luppi et al., 2009) that is the focus of this study, of about $60 \mathrm{~m}$ in length (Figure 1C). The average gradient of the reach here is 0.0021 , while the median grain diameter of the surficial bed material is about $22 \mathrm{~mm}$ on the point bar, and $37 \mathrm{~mm}$ on riffles (Luppi et al., 
2009). Both Rinaldi et al. (2008) and Luppi et al. (2009) cite the importance of fluvial erosion as a long term (seasonal) driver of bank erosion due to its role in inducing mass wasting processes and in subsequently removing failed material from the bank toe.

A full description of the bank morphology and sedimentology is provided by Rinaldi et al. (2008), but the general bank material stratigraphy is arranged as shown in Figure 1B. Although the stratigraphy is quite variable and includes several sedimentary layers, the bank is in essence composed of a cohesive upper portion (layers 3-5) overlying a gravel toe (layers $1-2)$, as is commonly the case in upland and piedmont zones in Europe and elsewhere (Rinaldi et al., 2004; Darby et al., 2007), but it is distinct from the fine-grained bank settings that are more usually associated with lowland environments and which have been the subject of related research (e.g. Simon et al., 2000; Simon and Collison, 2002). We note that this very active reach of the Cecina has been almost devoid of vegetation during the period of study, meaning that the added complexity of vegetation induced roughness does not need to be accounted for at the site.

As noted above, intensive bank erosion investigations at this study site have been ongoing since 2003 , meaning that much of the data required for the new analyses reported here are already available. However, of key importance for this study is the availability of highresolution bank topographic models derived from a series of photogrammetric and terrestrial laser scanning (TLS) surveys (see section 3.4 for full details of the methods employed in developing the topographic models) which offer an opportunity to precisely discriminate changes in bank morphology and hence roughness over a relatively long study period (20052011). These changes can also be contextualised in relation to the range of flow events experienced during this study period (Figure 2 and Table 1). Estimates of flow discharge are available from the nearby Ponte di Monterufoli gauging station from 1935, albeit with 
periods of interruption during 1943-50, 1963-68, 1977-78, 1982, 1988, and 1992. However, most pertinent to this study is the point that the station was also not functional during the period $22^{\text {nd }}$ August 2006 to $1^{\text {st }}$ January 2008. While water levels have subsequently been recorded, discharge estimates are not available from 2008 onwards as a new calibration of the stage-discharge rating curve is required but has not yet been carried out. We therefore use estimates of flow discharge derived from a hydrological model, as discussed in the next section.

\subsection{Hydrological Model for the Cecina River}

Estimates of flow discharge at Ponte di Monterufoli are derived using the MOBIDIC hydrological model developed for the Arno River Basin Authority (Castelli et al., 2001; Campo et al., 2006). MOBIDIC is a distributed, raster-based hydrological balance model that represents the hydrological cycle by simulating a series of reservoirs (representing each component of the hydrological system) and fluxes between them. The model employs a distributed mass balance for surface water and for water in the top soil, whereas deeper water is represented through a lumped approach at the catchment scale (Campo et al., 2006). The model employs a conceptual subdivision of soil water in each cell into two reservoirs associated with capillary (small scale pores) and gravitational (large scale pores) water flow, with the threshold pore size set at $60 \mu \mathrm{m}$ (Campo et al., 2006). Interested readers are referred to Campo et al. (2006) for full details of the process sub-models used in MOBIDIC to transfer water fluxes between the reservoirs and to ultimately route surface water through a catchment.

As employed in this study, the Cecina basin topography is represented using a $400 \mathrm{~m}$ DEM and MOBIDIC is forced with hourly resolution meteorological data (precipitation, temperature, humidity, wind speed and solar radiation) from a network of 15 meteorological 
stations located within the Cecina catchment. Hydrological properties such as infiltration velocity, soil capillary and gravitational capacity were derived by means of look-up tables from a raster pedological map, the latter itself derived from an original 1: 1,000,000 vector dataset (Mancini, 1966).

A comparison of simulated flow discharges with those observed during the period February to April 2006 indicates that this model provides 'very good' (Henriksen et al., 2008) predictions, with a Nash-Sutcliffe index of 0.737 and root mean square error (RMSE) of 3.6 $\mathrm{m}^{3} / \mathrm{s}$ (Figure 2). Note that the full period of overlap between simulated and observed (from the Ponte di Monterufoli gauging station) data is 1st January 2006 to 22nd August 2006. However, data for January 2006 were excluded from the validation analysis to allow a month-long model 'spin-up' period, while data from 1st May 2006 to 22nd August 2006 were also excluded to avoid periods of zero flow during the dry season months. The predictive performance of MOBIDIC as assessed during this contracted validation period is sufficiently good for the purpose of estimating the relative magnitude of peak flows encountered during the monitored epochs of bank erosion (Table 1). However, we note the caveat that the maximum peak observed during the February to April 2006 validation period is only 66.4 $\mathrm{m}^{3} / \mathrm{s}$, which is much smaller than the largest peaks observed over the broader study period (Figure 2). 


\subsection{Modelling the Form and Skin Drag Components of River Bank Roughness}

In this paper we employ Kean and Smith $(2006 a, b)$ to partition the drag on bank roughness elements into its form and skin drag components, the latter being the stress that is relevant for fluvial bank erosion:

$$
\tau_{T}=\tau_{S F}+\tau_{d}
$$

Kean and Smith's (2006a) model (see Figure 3) is based on a model of depth-averaged flow over dunes developed by Smith and McLean (1977) and McLean and Smith (1986). In this approach, equation (2) is written as (Kean and Smith, 2006a):

$$
\tau_{T}=\rho\left\langle u_{* I B L}\right\rangle^{2}+\frac{1}{2} \rho C_{D} \frac{H}{\lambda} u_{r e f}^{2}
$$

where $\rho$ is the fluid density, $u_{* I B L}$ is the shear velocity within the internal boundary layer (see Figure 3), $u_{r e f}$ is a reference flow velocity (see below), $H$ and $\lambda$ are geometrical parameters describing the protrusion height and crest spacing of the bank roughness elements, respectively, and the drag coefficient $\left(C_{D}\right)$ is estimated using a function derived from the experimental data of Hopson (1999):

$$
C_{D}=1.79 \exp \left(-0.77 \frac{\sigma}{H}\right)
$$

In equation (4), $\sigma$ is a third bank geometrical parameter which describes the streamwise length scale of Gaussian-shaped (see below) bank roughness elements. 
In equation (3), the square of the reference velocity is defined as being the average of the square of the velocity that would be present at the location of a roughness element if that element was removed from the flow (Kean and Smith, 2006a). Figure 3 shows that $u_{r e f}$ is affected by three interdependent regions: an internal boundary layer region, a wake region, and an outer boundary layer region. To calculate $u_{\text {ref }}$, the velocity field within each region must be determined, joined using matching conditions (see Kean and Smith, 2006a) and then spatially-averaged over the area of the obstacle of interest. The spatial-averaging requires an assumption to be made about the element's geometry. Based on their observations of numerous bank roughness elements, Kean and Smith (2006a,b) suggested that river bank roughness elements can appropriately be approximated as Gaussian-shaped 'bumps' (see Figure 3), an assumption that has also been found to be well met by other researchers (Darby et al., 2010; Nardi et al., 2013).

Regarding the methods employed to estimate the velocity field, within the internal boundary layer region the velocity is defined by the law of the wall (Kean and Smith, 2006a):

$$
u=\frac{u_{* I B L}}{\kappa} \ln \frac{z}{z_{o S F}}
$$

where $\kappa$ is von Karman's constant, $z$ is the distance away from the boundary, $z_{O S F}$ is the local roughness height of the boundary without topographic roughness elements, and $u * I B L$ is the shear velocity within the internal boundary layer. The flow in the outer region likewise follows the law of the wall:

This article is protected by copyright. All rights reserved. 


$$
u=\frac{u_{*_{T}}}{\kappa} \ln \frac{z}{z_{o T}}
$$

where $u *_{T}=\sqrt{\tau_{T} / \rho}$ and $z_{o T}$ is the roughness height due to skin friction plus form drag. In contrast, the wake-affected region is modelled using Schlichting's (1979) far-field wake solution, which is written:

$$
u=u_{b}\left[1-g(x) f\left(\frac{z-\eta}{b}\right)\right]
$$

within which Kean and Smith (2006a) use

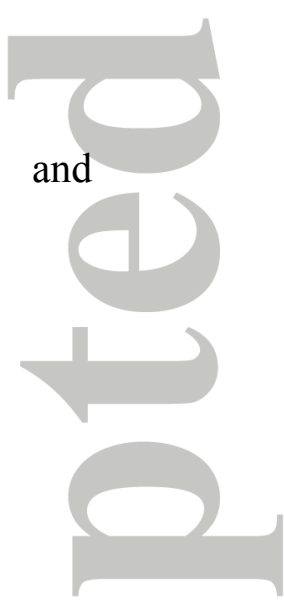

$$
g(x)=A_{2}\left(\frac{x+x_{o}}{C_{D} H}\right)
$$

$$
f\left(\frac{z-\eta}{b}\right)=\left[1-\left(\frac{z-\eta}{b}\right)^{3 / 2}\right]^{2}
$$

where $x$ is the distance downstream from the centre of the element producing the wake, $z$ is the distance away from the reference level of the roughness elements, $z=\eta$ is the surface of the boundary, $u_{b}$ is the velocity at the top of the wake, $x_{o}$ is the virtual origin, which Kean and Smith equate to zero, and the wake thickness, $b$ (Figure 3), is given by (Kean and Smith, 2006a):

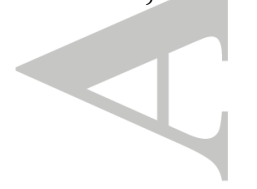




$$
b=2 A_{1} C_{D} H\left(\frac{x+x_{o}}{C_{D} H}\right)^{1 / 2}
$$

The constants $A_{1}$ and $A_{2}$ are defined by Kean and Smith (2006a) using data from flume experiments. A critical aspect of the Kean and Smith model lies in applying the velocity matching conditions between the internal boundary layer and wake, and between the wake and the outer flow region. Full details of both of these matching conditions are reported in Kean and Smith (2006a). Suffice here to note that equations (5), (6) and (7), together with the corresponding velocity matching conditions, fully specify the velocity field, $u(x, z)$, which is then spatially-averaged (over the roughness element) to obtain the reference velocity for use in equation (3).

Kean and Smith (2006a,b) provide full details of the procedures used to close the above set of equations, but in summary initial estimates are made of the total roughness height and shear velocity, $z_{o T}$ and $u *_{T}$, in a region of the flow, termed the outer flow region, that is sufficiently distant from the riverbank to be unaffected by any wakes shed by the bank roughness elements. These initial estimates are made by fitting a logarithmic velocity profile to a (user) specified value of the velocity, $u_{\text {out }}$, at a point in the outer flow region located at a distance $z_{\text {crit }}$ from the bank. This estimation procedure then enables $\left\langle u_{I_{I B L}}\right\rangle$ and $u_{r e f}$ in equation (3) to be determined by means of separate methods within the regions of the near-bank flow affected and not affected by wakes, from which improved estimates of $u *_{T}$ and $z_{o T}$ are obtained. This iterative sequence is repeated until the solution converges.

\footnotetext{
The necessary input data requirements to solve the Kean and Smith model therefore include a set of parameters describing the geometrical characteristics of the bank roughness elements
} 
$(H, \sigma, \lambda)$, an estimate of the roughness height associated with the skin drag component of the boundary shear stress $\left(z_{o S F}\right)$, along with a specified flow velocity within the outer flow region, $u_{\text {out }}$, at a distance from the boundary, $z_{\text {crit }}$. In this study we use a $z_{\text {crit }}$ value of $10 \mathrm{~m}(\sim 2.5$ times the bank height) which is assumed to be at a location sufficiently distant from the bank to be safely outside the zone affected by wakes, whilst not being so distant that the local shear stresses are influenced unduly by transverse variations in channel depth. The outer region flow velocity, $u_{\text {out }}$, at $\mathrm{z}_{\text {crit }}$ was estimated from depth-averaged DELFT3D (WL Delft Hydraulics, 2006) simulations undertaken by Rinaldi et al. (2008). For details of the setup of the model and the full simulation results the reader is referred to this original study, but herein the maximum flow velocity at $z_{\text {crit }}$ of $3.34 \mathrm{~ms}^{-1}$ was used to define the outer flow region velocity matching term. Whilst the choice of $\mathrm{z}_{\text {crit }}$ may seem arbitrary, herein it is used only to indicate the ratio of shear forces that together define the total stress. We note that sensitivity analysis of the Kean and Smith method, using $\pm 1 \sigma\left(1.12 \mathrm{~ms}^{-1}\right)$ of the distribution of modelled flow velocities results in no change in the ratio of $\tau_{S F}$ to $\tau_{D}(1: 1.5)$.

Following Hopson (1999), and as discussed above, Kean and Smith (2006a) approximate natural river bank topographical elements as a series of Gaussian curves (Figure 3B). This means that $H, \sigma$ and $\lambda$ can be easily estimated for each fitted curve and the skin friction element of the shear stress, $z_{O S F}$, is assumed to be represented by the residuals of the data points from the fitted Gaussian function. For a given sequence of irregularly sized and spaced bumps, Kean and Smith (2006b) show that $H, \sigma$ and $\lambda$ can be regularised into a reach-scale average using the $88^{\text {th }}$ percentiles such that:

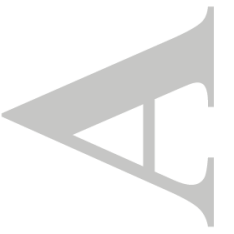

$$
\begin{gathered}
H_{r e g}=H_{88} \\
\sigma_{r e g}=\sigma_{88}
\end{gathered}
$$




$$
\lambda_{\text {reg }}=6 H_{88}
$$

These values can then be used to solve Equation 3 using Equation 4. The skin friction, $z_{o S F}$, is similarly reach-averaged through analysis of the residuals from the fitted Gaussian distributions. Kean and Smith (2005) recommend that characteristic wavelengths in the secondary roughness should be identified using Fourier analysis. If a significant peak in wavelength is detected then the skin friction can be modelled as a sine wave of the characteristic frequency. If no dominant wavelength is detected, as in this study, Kean and Smith (2005) approximate $z_{o S F}$ as a tenth of the standard deviation of the residuals, analogous to the relationship $z_{o S F}=0.1 D_{84}$ used for granular surfaces. The results of the analysis are vertically aggregated, reach averaged estimates of the components of the total boundary shear stress.

\section{stress.}

(

\subsection{Bank DEM Data and Processing}

A data series characterising the detail of the bank topography of the study reach described in section 3.1 was collected over a six year period (2005-2011). Data collection involved a combination of high resolution digital photogrammetric and Terrestrial Laser Scanning (TLS) surveys. Details of the dates of each of the surveys and summary statistics of the resultant elevation models, as well as the corresponding hydrological data for each epoch of interest are summarised in Table 1.

Photogrammetric field data collection involved deploying a series of 24 numbered control points approximately $10 \mathrm{~m}$ apart in three transects (top, middle and bottom of bank) along the reach of interest. These control points were surveyed into the local Gauss Boaga Italian coordinate system using a combination of an RTK dGPS, used to reference four local 
benchmarks, and a total station which was used to acquire the photogrammetric control markers. A calibrated Nikon D100 digital camera set at a focal length of $24 \mathrm{~mm}$ was deployed from 5 tripod locations, approximately $30 \mathrm{~m}$ from the bank face. Overlapping images were acquired along the bank with a resultant pixel size that represents a mean bank area of $0.0004 \mathrm{~m}^{2}$. Processing of the images was undertaken using the Micromap software package, whereby the control point locations and camera geometry information is used in conjunction with an automated algorithm for point cloud creation. The resultant models have a mean point density of $\sim 2000$ points per $\mathrm{m}^{2}$, a mean point spacing of $0.029 \mathrm{~m}$, and a surface positional error of $\pm 0.021 \mathrm{~m}$ (see below), both well below the $0.05 \mathrm{~m}$ spacing of the data used by Kean and Smith (2005). For analysis and discussion surrounding the potential scale dependence of the Kean and Smith $(2005 ; 2006 a$,b) method, see section 3.6.

Terrestrial Laser Scanning (TLS) of the reach was undertaken in 2008 and 2011 using a Leica Scanstation. The Scanstation is a time of flight sensor that uses a $523 \mathrm{~nm}$ green laser pulse to measure $\mathrm{x}, \mathrm{y}, \mathrm{z}$ survey locations at speeds of up to $4 \mathrm{kHz}$. The TLS was deployed from three scan locations; the upstream extent of the reach, the downstream extent of the reach and in between the two. Four targets were deployed around the reach (ensuring a good spread around the scan locations) and these were surveyed in using a reflectorless total station that was re-sectioned into the Italian Gauss Boaga coordinate system using the four dGPS acquired benchmarks described above. At each location a full bank scan was completed using a series of adjacent smaller scan areas to maintain a consistent spatial resolution in the data. The multiple locations were registered to one another using the targets (RMSE between coregistered scans $<0.004 \mathrm{~m}$ ) and the convergent scans were found to minimise the effects of shadowing, producing point clouds with a mean density of 250,000 and 444,000 points per $\mathrm{m}^{2}$ and a mean spacing of 0.002 and $0.0015 \mathrm{~m}$ in 2008 and 2011, respectively. 
The TLS data required some manual point removal of redundant data such as vegetation on the top of the bank; this was undertaken in Leica Cyclone, the proprietary software used to collect and analyse Leica Scanstation TLS data. Due to the lack of vegetation on the bank faces no filtering and minimal manual removal of points was required. All of the point clouds (TLS and photogrammetric) were then imported into a single model viewer in Cyclone. At this stage the data was re-projected from the Italian Gauss Boaga west system to an arbitrary local co-ordinate system where, importantly, the $\mathrm{x}$ axis was aligned with the downstream trend of the bank and the y axis was re-projected to represent the bank elevation ( $\mathrm{z})$. The new coordinate system allowed the data to be exported in text format for subsequent loading as a series of eight point layers in ArcGIS (v.10, sp3), ensuring that ArcGIS displayed a view of the bank face rather than a plan view of the bank curvature. ArcGIS was used to create triangular irregular networks (TINs) of the point clouds which interpolate areas of no data whilst maintaining the integrity of the original data sets. These high resolution bank model TINs were used as the base models for extraction and analysis of the roughness metrics explained below.

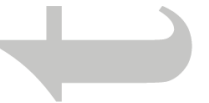

The high resolution TINs were next converted to a set of high resolution $(0.05 \mathrm{~m})$ raster grids (Figure 4) so that analysis of bank forms and volumetric erosion and deposition could be undertaken through the production of DEMs of difference (DoDs) for each epoch of change (Figure 5). DoDs are created by subtracting one DEM from another to produce a surface that represents the magnitude of change that has occurred on a cell by cell basis in the time between the two surveys. DoDs are thus useful to examine directions and magnitudes of change through time in fluvial regimes, often in relation to bed form erosion and deposition (e.g. Brasington et al., 2000; 2003; Milan et al., 2007; Wheaton et al., 2010; 2013). A theme common to all of these previous studies is that the data collection techniques employed are 
subject to some uncertainty which will propagate through to any subsequent DoD analysis, meaning that any change is subject to a minimum level of detection (LoD). A range of techniques are suggested to account for such uncertainty and define LoDs, ranging from ground truthing of DEM accuracy (Wood, 1996) to sophisticated spatially distributed methods that use fuzzy set theory and coherence filters based on Bayes Theorem (Wheaton et al., 2010). In this study the focus is not on producing accurate estimates of volumetric erosion or deposition, rather the DoDs are used as a means to help explain relative changes in the metrics of roughness in terms of dynamic bank shift. We therefore employ the relatively simple uniform error assessment proposed by Brasington et al. (2003) to define the minimum LoD $\left(L o D_{\min }\right)$ for the Cecina bank surveys:

$$
L o D_{\min }=\sqrt{\left(\partial Z_{\text {old }}\right)^{2}+\left(\partial Z_{\text {new }}\right)^{2}}
$$

where $\delta Z_{\text {old }}$ and $\delta Z_{\text {new }}$ are the errors in the individual DEMs being compared. The errors associated with TLS surveys are very small compared with traditional survey techniques such as total station, dGPS and photogrammetry. The modelled surface error reported by the manufacturer of the Leica Scanstation used in this study is $0.002 \mathrm{~m}$, scan registration errors for the Cecina surveys were all $<0.004 \mathrm{~m}$ and the dGPS positional accuracy was $<0.015 \mathrm{~m}$ for all surveys. These were combined to give a maximum TLS survey error of $0.021 \mathrm{~m}$. Photogrammetric survey errors are harder to quantify so in this study we took advantage of having produced both a photogrammetric and TLS survey of the river bank in September 2008. Using the TLS survey as a benchmark (accepting the aforementioned errors) the photogrammetric survey was subtracted to create a DoD (Figure 5A). Aside from a small area in a deep embayment at the left edge of the DoD where the photogrammetry derived depths were poor, the survey was highly accurate and the mean absolute error was calculated as 
$0.008 \mathrm{~m}$. When combined with the positional error, the maximum photogrammetric survey error was $0.029 \mathrm{~m}$. Therefore the calculated $L o D_{\min }$ for the Cecina DoDs was $0.035 \mathrm{~m}$, and values below this threshold were not included in DoD analysis (Figure 5B).

\subsection{Estimating Bank Roughness Parameters}

The Kean and Smith $(2006 a, b)$ methodology of partitioning the form and skin drag components of the shear stress exerted on a river bank relies on defining metrics that describe the nature of the topographic elements protruding into the flow. As described in section 3.3, a series of Gaussian bumps are used to described $H$, the protrusion distance of the Gaussian curve, $\sigma$, the streamwise span (equivalent to the standard deviation of a Gaussian pdf) and $\lambda$, the spacing between modelled crests, with the skin friction element of the shear stress, $z_{o s F}$, assumed to be represented by the residuals of the data points from the fitted Gaussian curves.

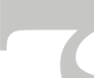

The Cecina River has distinct bank units which map onto the stratigraphic units present at the site (Figure 1B) and these five units were used as the basis for defining profiles for extraction along each DEM (Figure 6A). Subsequent analysis described below vertically aggregates the five profiles for each survey to obtain the reach averaged values for each epoch.

Profiles were extracted using the 3D analyst toolbox of ArcGIS 10.1. Specifically, five polylines were constructed centred on the bank units as described above. The polylines were converted to $3 \mathrm{D}$ using elevations derived from TINs of the point clouds. These polylines were then exported to text files as profile data, formatted as a cumulative distance and a distance from a survey plane. The text files are used as input into a bespoke Matlab script (KSGaussFit; available for download at: http://www.leyland/org.uk/downloads) which allows the operator to define protruding bank elements (top panel of Figure 6B). When all elements 
have been defined the profile is detrended (middle panel Figure 6B) and Gaussian profiles are fitted to each of the 'bumps' defined by the user (bottom panel Figure 6B). The height, profile length and spacing statistics of the fitted bumps equate to $H, \sigma$ and $\lambda$. The residuals of the fitted data to the Gaussian curves are used as the basis for defining the skin friction, $z_{o S F}$. Analysis of the residuals using a Fast Fourier Transform function revealed no characteristic wavelengths in the data, so $z_{O S F}$ was calculated as a tenth of the standard deviation of the residuals as described above. All statistics, along with a range of other metrics including the $R^{2}$ and root mean squared error of the Gaussian fits, are stored in a text file for each profile. Note that the irregular sequences of Gaussian profiles produced herein were regularised using the relationships of Equation (11) as suggested by Kean and Smith (2006b)

\subsection{Scale dependence of Kean and Smith analysis}

The ultra-high resolution TLS survey of 2011 (see Table 1) provides a benchmark dataset with which to analyse the extent to which the Kean and Smith $(2006 a, b)$ method might be susceptible to issues of scale dependence relating to the spatial resolution of the survey data. A profile was extracted from the survey and analysed using the KSGaussFit code as per the standard methodology described in section 3.5. The mean point spacing of this raw profile was $0.0015 \mathrm{~m}$. The profile spacing was then repeatedly resampled at twice the previous point spacing, up to a maximum spacing of $0.4 \mathrm{~m}$, and the analysis re-run in Matlab. Figure 7 shows the resultant change in Kean and Smith (2006a) metrics as a function of increasing profile point spacing.

Estimates of $H, \sigma$ and $\lambda$ are consistent over a profile spacing range of 0.0015 to $0.024 \mathrm{~m}$, but at coarser sampling intervals it is evident that there is some divergence in the estimated roughness parameters, especially in estimates of $\lambda$, the crest spacing. This is an expected 
effect of increasing the profile sample spacing; as the number of points is reduced the number of identifiable Gaussian features is likewise reduced once a threshold spacing is exceeded. In the case of the Cecina this threshold spacing appears to be $0.048 \mathrm{~m}$, at which point the number of identifiable Gaussian features drops from greater than 190 for higher resolution profiles (where the maximum number is 212 for the $0.0015 \mathrm{~m}$ spacing) to 126 . Over this threshold, the number of features detected halves at each incremental point spacing increase, accounting for the increasing estimate of crest spacing shown in Figure 7. Conversely, estimates of $H$ and $\sigma$ appear to remain quasi-constant, with a slight divergence from $0.048 \mathrm{~m}$ and upwards. This implies that whilst less Gaussian features are being identified, those that are appear to be representative of the mean height and streamwise length of protrusions present in the profile. Values of $z_{o S F}$ are more sensitive to the point spacing of extracted profiles. For the Cecina River, values appear to converge towards a minimum estimate at a point spacing of $0.003 \mathrm{~m}$, below which the value of $z_{o S F}$ increases systematically. However, note that the difference in estimates of $z_{O S F}$ at either end of the scale on Figure 7 vary only by a factor of three compared with a variation of a factor of $\sim 10$ for the extremes of $\lambda$. Given that the skin friction component of the total shear stress is often observed to be an order of magnitude less than the form drag component (Kean and Smith, 2006a) and that the relative variations in $z_{O S F}$ are minimal, we herein define the maximum point spacing that is capable of providing accurate form metrics on the Cecina River as approximately $0.05 \mathrm{~m}$.

\section{RESULTS}

\subsection{Bank DEMs and roughness metrics}

Figure 4 shows the DEMs for each of the survey epochs identified in Table 1. All surveys broadly conform to the model of bank morphology for the reach shown in Figure 1B, with a steep vertical face at the top of the bank, an intermediate sandy silt layer that is slightly less 
steep and a significantly less steep bank toe consisting of unconsolidated gravels and cobbles. The larger scale bank morphology along the study reach of the Cecina River has been dominated by the presence and decline of an embayment at the upstream (left on figure 4) extent of the bank. In S1 (February 2005) this embayment extended approximately 5-6 m into the bank face and had a maximum vertical extent of $3 \mathrm{~m}$. The time series of DEMs reveals how the embayment is reduced in extent as the surrounding bank is eroded away, although in S6 (September 2008), the embayment appears to have been enlarged in the downstream direction. By the time of survey S8, the embayment has been reduced to less than $1 \mathrm{~m}$ high and $3 \mathrm{~m}$ wide in extent. In conjunction with the decline of the upstream embayment, from S7 to S8 (July 2010 - July 2011) a new embayment is formed at the downstream limit of the reach. This feature appears to form rapidly over the course of a year, extending $\sim 4 \mathrm{~m}$ deep, 2 $\mathrm{m}$ in vertical extent and approximately $5 \mathrm{~m}$ in the streamwise direction (from the $40 \mathrm{~m}$ mark on Figure 4, S8). The remains of the upstream embayment and the newly formed downstream feature are clearly visible on the composite photo and on the S8 DEM. The inclusion or otherwise of an embayment in a DEM does not appear to have an effect on the derived roughness parameters (see Table 2), as the features are larger than the manually defined form roughness elements. This exclusion of larger bank form roughness elements is a potential source of uncertainty in using the Kean and Smith methodology and is explicitly discussed in relation to scales of roughness in the discussion section below.

Throughout the course of the surveys, the banks have also shown subtle differences in morphology. Relative to the other broadly self-similar surveys, S5 appears to display a higher amplitude form roughness. This is confirmed by the extracted value of $\lambda$ which is $1.23 \mathrm{~m}$ for S5 compared with a mean of 0.79 for the other surveys. Likewise Table 2 shows that for some surveys (e.g. S2 and S6) many more form roughness elements exist, as evidenced from 
the number of Gaussian bumps fitted to them relative to the other surveys. Interestingly, the mean shape of those bumps, characterised by $H_{\text {reg }}$ and $\sigma_{\text {reg }}$, are very similar to the other surveys with $H_{\text {reg }}$ values of $0.15 \mathrm{~m}$ and $0.11 \mathrm{~m}$ and $\sigma_{\text {reg }}$ values of $0.24 \mathrm{~m}$ and $0.29 \mathrm{~m}$ for S2 and S6, respectively. The survey displaying the greatest roughness in terms of bump height is S5, with a value of $H_{\text {reg }}$ of $0.20 \mathrm{~m}$, compared to $H_{\text {reg }}$ of $0.11 \mathrm{~m}$ for $\mathrm{S} 6$, the survey revealing the least protruding roughness elements.

Table 2 presents details of the metrics extracted from the fitted Gaussian curves, including the total number of identified bumps and the mean goodness of fit for each set of functions expressed as an $\mathrm{R}^{2}$ value calculated from the residuals. The $\mathrm{R}^{2}$ values reveal that the form roughness elements of the Cecina can be reasonably approximated by Gaussian curves, with values ranging from 0.60 to 0.89 with a mean across all surveys of 0.74 . We note though that these $\mathrm{R}^{2}$ values do not confirm or otherwise that the roughness elements are truly Gaussian in nature. The decision to vertically aggregate the profiles for each epoch was taken in the interests of presenting results applicable at a bank reach scale. However, Table 2 reveals that when profiles for all epochs from each of the five bank units (termed BU1 to BU5 in Figure 1) are temporally averaged, any distinct difference in total roughness is smoothed out with the exception of BU4 (silt and clay supported gravel) which appears to exhibit a consistently lower total roughness height.

\subsection{Statistical distributions of roughness parameters}

Whilst the Kean and Smith (2006a) method of partitioning the total stress relies on using reach averaged, regularised values for $H, \sigma$ and $\lambda$, the KSGaussFit Matlab routine produces these parameters for every fitted Gaussian bump, meaning that for each survey there is a distribution of data available. Figure 8 shows the full data distribution for each of the 
extracted metrics and for important combinations of the parameters as suggested by Kean and Smith (2006b). Figure 8 reveals that there appears to be two dominant distributions of $\lambda$; a broad, flat distribution with a longer tail tending towards higher values (S1, S3, S4, S7) and a narrower, taller distribution with values clustered more tightly around a lower mean (S2, S5, S6, S8). Distributions of $H$ and $\sigma$ are broadly similar across the eight survey dates, with $H$ being dominated by very tightly clustered distributions and $\sigma$ characterised by slightly broader distributions of lower frequencies. The distributions of $\sigma / H$, defined as the primary measure of the shape of the bank roughness element by Kean and Smith (2006b), are typically also lower frequency, with the exceptions being provided by S2 and S5 which display narrower distributions with a relatively higher frequency occurrence at the low end of the distribution. These distributions accordingly exhibit the lowest regularised ( $88^{\text {th }}$ percentile) values of 2.98 and 3.82 respectively. Distributions of $\lambda / \sigma$, the ratio of the two streamwise length scales, reveal that S6 and S8 exhibit rapid declines in the frequency of higher values of this parameter, representing the two lowest regularised values of 4.61 and 4.08 respectively. The product of $C_{D}$ and $H$ is a measure of the intensity of the wake produced by flow past the bank roughness element (Kean and Smith (2006b) and distributions of this parameter are fairly uniform with the exception of the longer tails evident in S2, S3 and S5. These surveys exhibit the highest values of $C_{D} H$ at $0.15,0.20$ and 0.14 respectively.

\section{DISCUSSION}

\subsection{Temporal variations of roughness}

Hydraulic bank erosion is most commonly estimated using the excess shear stress formula (equation 1). The successful application of equation (1) depends upon our ability to parameterise the key elements of the model: the erodibility coefficient $(k)$, the skin drag component of the boundary shear stress $\left(\tau_{S F}\right)$, the critical shear stress $\left(\tau_{c}\right)$ and the exponent, $a$, although this is usually set to one. It has been shown by Darby et al. (2010) that $k$ and $\tau_{c}$ can 
be measured in the field using devices such as a Cohesive Strength Meter (CSM; Tolhurst et al., 1999). However, defining the total boundary shear stress across a range of flow conditions and in particular correctly partitioning of the skin $\left(\tau_{S F}\right)$ and form $\operatorname{drag}\left(\tau_{D}\right)$ components of the boundary stress, remains a challenge. The Kean and Smith $(2005 ; 2006 a$; 2006b) approach to estimating the two components of the boundary shear stress offers an attractive alternative to calibration, allowing the direct estimation of the relative magnitudes of $\tau_{S F}$ and $\tau_{D}$ based on high resolution topographic data and outer region flow field velocities. Given that $\tau_{S F}$ is the driver of fluvial erosion, it follows from equation (1) that it is the magnitudes of $\tau_{s f}$ relative to $\tau_{D}$ that controls rates of fluvial erosion. Whilst previous research (Darby et al., 2010; Nardi et al., 2013) has sought to quantify fluvial erosion rates using this approach no one has yet investigated the temporal evolution of $\tau_{S F}$ and $\tau_{D}$ in conjunction with detailed morphological data in an attempt to establish how erosion, morphology and shear stress co-evolve.

Figure 9 shows how the estimated boundary shear stress components of $\tau_{S F}$ and $\tau_{D}$ vary as a function of flow discharge. Here $\tau_{S F}$ and $\tau_{D}$ are calculated according to the Kean and Smith iterative solution of velocity matching the internal and outer boundary layer flow regions (see section 3.3 and Kean and Smith, 2006a for full details). In conjunction with the DEMs of Difference (DoD) presented in Figure 5 and the DEMs of Figure 4, the co-evolution of the Cecina River bank and associated estimated magnitudes of $\tau_{S F}$ and $\tau_{D}$ between survey dates are described below. Note that estimates of $\tau_{S F}$ and $\tau_{D}$ below are for bankfull conditions and as such are representative only of the potential partitioning of stress at a given point in time. However, we do discuss the evolution of bank form in relation to the modelled discharge time series and total erosion in an effort to tease out likely process-form interactions. 
- DoD 1 (February 2005 - August 2005): The starting morphology (Figure 4 S1) is characterised by large form elements such as embayments and protruding spurs. The form drag component of the boundary shear stress is correspondingly high ( $\tau_{D}=34.6$ $\mathrm{N} / \mathrm{m}^{2}$ ). The low flow conditions through the summer result in approximately uniform erosion $\left(13.2 \mathrm{~m}^{3}\right.$ or $2.2 \mathrm{~m}^{3}$ per month) of the bank during this epoch, leading to a continuation of high $\tau_{D}\left(33.5 \mathrm{~N} / \mathrm{m}^{2}\right)$ and a slightly increasing $\tau_{S F}$ from 9.8 to 11.7 $\mathrm{N} / \mathrm{m}^{2}$.

- DoD 2 (August 2005 - January 2006): This epoch is characterised by a series of relatively large flood events resulting in uniformly high rates of erosion (Figure 5B, DoD 2). If averaged by time, the $22.2 \mathrm{~m}^{3}$ total volumetric loss in this epoch gives a monthly rate of $4.4 \mathrm{~m}^{3}$. The uniform pattern of erosion means that bank form roughness is preserved, leading to a relatively stable high value of $\tau_{D}\left(33.1 \mathrm{~N} / \mathrm{m}^{2}\right)$ and a slightly increasing $\tau_{S F}\left(14.7 \mathrm{~N} / \mathrm{m}^{2}\right)$.

- DoD 3 (January 2006 - Jun 2006): Following the high magnitude erosion of DoD 2, persistent low flows $\left(<100 \mathrm{~m}^{3} / \mathrm{s}\right)$ during this epoch lead to highly targeted erosion focused on the slumped material at the bank toe (see Figure 4 S3) and bank protrusions. Analysis of Figure 5B DoD 3 reveals the targeted spatial distribution of the erosion, showing how the toe material is removed during this period of low flow. Although the volumetric rate of erosion is small (total $3.2 \mathrm{~m}^{3} ; 0.64 \mathrm{~m}^{3}$ per month; see Figure 9), the form roughness of the bank is visibly reduced, highlighted by the reduction in the regularised fitted bump height from 0.15 to $0.13 \mathrm{~m}$ (Table 2). We term this epoch of erosion a 'trimming phase' based on the reduction in $\tau_{D}$ from 33.1 $\mathrm{N} / \mathrm{m}^{2}$ in the previous epoch to $23.1 \mathrm{~N} / \mathrm{m}^{2} \cdot \tau_{S F}$ remains broadly stable at $12.2 \mathrm{~N} / \mathrm{m}^{2}$, indicating that the bank material and micro-topography is largely unaffected by the 
large scale erosion of this epoch. The drop in $\tau_{D}$ relative to $\tau_{S F}$ leads to an increased potential for erosion beyond this period.

- DoD 4 (June 2006 - February 2007): The winter high flows of this period bring about concentrated patches of erosion which appear to result in the creation of additional protrusions (Figure 5B DoD 4). This roughens the bank surface, forcing $\tau_{D}$ to return to a pre-trimming value of between $30-35 \mathrm{~N} / \mathrm{m}^{2}\left(34 \mathrm{~N} / \mathrm{m}^{2}\right.$ in this case) with a corresponding increase in the regularised fitted bump characteristics ( $\lambda$ and $H$ almost doubling between the two surveys from 0.77 to $1.23 \mathrm{~m}$ and 0.13 to $0.20 \mathrm{~m}$ respectively, see Table 2). As per the epoch described by DoD3, the volumetric rate of material loss is small (total $3.8 \mathrm{~m}^{3} ; 0.48 \mathrm{~m}^{3}$ per month) but the erosion appears to be characterised by small areas of concentrated failure (most likely mass wasting events triggered by fluvial erosion) which increase $\tau_{D}$. $\tau_{S F}$ continues to remain broadly stable at $14.3 \mathrm{~N} / \mathrm{m}^{2}$. We note that there is a flow event exceeding $600 \mathrm{~m}^{3} / \mathrm{s}$, amongst the highest discharges recorded or modelled in the six year period (Figure 9). Despite the relatively low total volume of erosion, the flood event is very likely to have induced localised failures which result in the high form drag at the end of the epoch.

- DoD 5 (February 2007 - September 2008): This long epoch results in a large decrease in $\tau_{D}$ from 34 to $14 \mathrm{~N} / \mathrm{m}^{2}$. The period encompasses $\sim 1.5$ years and so it is difficult to propose erosion mechanisms with any certainty, but approaching survey 6 (Figure 4 S6), the low flows of the summer period are likely to have prompted a trimming phase, resulting in the large reduction in $\tau_{D}$ (from 34 to $14.3 \mathrm{~N} / \mathrm{m}^{2}$ ) The regularised bump metrics support this notion, displaying a modest decrease across $H, \sigma$ and $\lambda$ (see Table 2 for details). $\tau_{S F}$ remains broadly stable at $9.2 \mathrm{~N} / \mathrm{m}^{2}$. Total volumetric erosion is $10.1 \mathrm{~m}^{3}$ over the epoch, resulting in a monthly rate of $0.53 \mathrm{~m}^{3}$. 
- DoD 6 (September 2008 - July 2010): Despite moderate winter flow events the increased potential for erosion brought about by the large reduction in $\tau_{D}$ in DoD 5 results in a period of intense erosion (Figure 5B DoD 6). Once again this epoch covers a longer period at 22 months, but when volumetric erosion is averaged over time, it still accounts for amongst the highest rates of loss at $1.4 \mathrm{~m}^{3}$ per month with a total loss of $29.6 \mathrm{~m}^{3} . \tau_{D}$ increases to a 'pre-trimming' level of between $30-35 \mathrm{~N} / \mathrm{m}^{2}$ relative to $\tau_{S F}$ which remains stable at $9 \mathrm{~N} / \mathrm{m}^{2}$, reducing the potential for erosion in subsequent flows.

- DoD 7 (July 2010 - July 2011): The epoch is characterised overall by another trimming phase, with $\tau_{D}$ reduced to $5.2 \mathrm{~N} / \mathrm{m}^{2}$ by the time survey 8 is recorded (Figure $4 \mathrm{~S} 8$ ). Similarly, erosion rates drop to just $0.32 \mathrm{~m}^{3}$ per month from a combined loss of only $3.8 \mathrm{~m}^{3}$. Although $\tau_{S F}$ is typically stable between surveys at $9-15 \mathrm{~N} / \mathrm{m}^{2}$, it rises to $21 \mathrm{~N} / \mathrm{m}^{2}$ at survey 8 , resulting in a large increase in the potential for erosion following the last survey. As no further surveys have been undertaken, large scale erosion events at the site cannot be confirmed.

\subsection{A conceptual model of a self-limiting erosion mechanism}

The morphological development of the Cecina River bank and the co-evolving magnitudes of $\tau_{S F}$ and $\tau_{D}$ over a six year period can be formulated into a hypothesised conceptual cycle as outlined in Figure 10 and the four stages summarised thus:

1. The form drag component of the total boundary shear stress can be altered instantaneously by bank failures induced by fluvial-erosion driven undercutting during high flow events. Due to the nature of the failures in the study reach (Luppi et al. 2009) the hydraulic response is typically an increase in $\tau_{D}$ as a result of the 
creation of embayments and protrusions, and the deposition of rough failure debris at the toe (Parker et al., 2011). The increased form roughness subsequently protects the bank from further erosion by increasing the size of the near-bank boundary layer region and increasing the magnitude of $\tau_{D}$ compared to $\tau_{S F}$.

2. Subsequent flows preferentially 'trim' the form roughness elements created in the preceding phase, resulting in a decrease in $\tau_{D}$ and commensurate increase in $\tau_{S F}$, thereby increasing the potential for erosion. Whether such erosion actually occurs depends on the occurrence of subsequent competent flows.

3. At lower flows continued trimming, smoothing and removal of bank toe material deposited from failures occurs, resulting in a further decrease in $\tau_{D}$ compared to $\tau_{S F}$ and therefore an increased potential for erosion. Note that this potential may not be fully realised unless higher flows occur (see Stage 4, below). Note also that this stage (Stage 3) may be bypassed if there is not adequate time or a sufficient succession of low flows, before a new erosive high flow occurs (i.e. the bank response may skip directly to stage 4).

4. At the next period of high flow, the heightened erosion potential leads to likely failures and a return to stage one of the cycle.

Analysis of Figure 9 reveals that evolution of form roughness on the Cecina broadly follows the stages of evolution of the proposed model. This implies that the evolution of the banks is well coupled to seasonal variations in discharge, with the trimming phase associated with low summer flows. However, there are some instances where the data do not follow the proposed model, e.g. the high form roughness measured in July and August at S2 and S7 respectively. In the case of $\mathrm{S} 2$ this can be attributed to the fact that there were a very limited number of low flow 'trimming' events in the following summer period (Figure 9), so the form roughness 
inherited from the preceding higher winter flows persists through those months. On the contrary, in the case of S7 it seems there was a sequence of several relatively higher flow events during the late spring to beginning of summer (Figure 9), which we surmise were sufficiently intense to induce high rates of fluvial erosion and thus trigger mass failures and therefore induce a transition from stage 2 directly to stage 4 , skipping stage 3 . Indeed, the study of Luppi et al. (2009) revealed through modelling that mass failures induced by fluvial undercutting typically occurred for flow events with $Q>168 \mathrm{~m}^{3} / \mathrm{s}$. Taking this as an approximate threshold for hydraulically-induced mass failure along the studied bank, in the period immediately before S7 there were two such flow events exceeding this threshold. The role of larger flood events is likely important in terms of triggering the mass-wasting events that increase form roughness and further work is required to quantify the relative impact of them on the evolution of bank form. Notwithstanding this variability, there is a clear seasonality in the temporal evolution of the bank form along the Cecina River. Generally, most failures occur during autumn and winter due to the prolonged and multi-peaked events, while spring and summer are normally characterized by intermediate to low events (stages 2 and 3). As shown in Figure 9 though, events triggering mass failures can also occur in spring, indicating that progression through the full four stages of the model depends not only on the seasonality, but also on the succession of variable magnitude flow events.

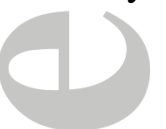

The conceptual model proposed herein is analogous to the basal endpoint control mechanism originally proposed by Carson and Kirkby (1972) and later developed by Thorne (1982), whereby failed material from a bank protects the toe from further erosion by temporarily impeding further erosion. Basal endpoint control theory has emphasized the role of sediment supplied from the bank acting as protection. The current formulations of bank retreat models neglect the explicit effects of this protection, with the exception of recent work by Parker et 
al. (2011). In fact, the feedback model we outline herein further strengthens the theory of basal endpoint control by providing an additional mechanism by which river banks can reduce the erosive energy imparted on them via an instantaneous increase in form drag following mass wasting.

We recognise that this study and the methods it employs raises some important questions that might be addressed in future research. Firstly, the methods currently used to define the form elements to which Gaussian curves are fitted are rather subjective and do not take into account the likelihood that roughness is multi-scaled, depending upon the user to define the minima of the roughness elements using the KSGaussFit code. Therefore the resultant scales of roughness are likely to be a function of the smallest scale of 'bump' observable by the operator, with larger form elements likely detrended out of the profile. The authors have explored some automated curve fitting methods, but the complexity of the data (no predefined scales for curves) and the bank curvature trends make automating the process difficult. Further efforts are required on this front. Secondly, there are questions regarding the nature of the spatial distribution of roughness in natural systems. Kean and Smith's (2006a) method treats the roughness elements as two-dimensional in nature, aggregating the vertical differences into a set of reach averaged metrics. Therefore, it is the vertical profile spacing that controls the scale of the vertical variations in form elements that are captured in the extracted metrics. Kean and Smith (2006b) themselves conclude that future work might extend the approach to address how three-dimensional topographic features affect flow. Recent studies looking at surface roughness have made use of three-dimensional characterisations such as Fourier transform radial spectra (Nield et al., 2013), which have the advantage of highlighting the dominant direction of the roughness patterns as well as the wavelengths. Such methods might offer an alternative method for extracting form elements 
from DEM data, with the obvious secondary advantages of making use of the full bank DEM and of being automated. Linked with this topic is the question of averaging domains; the present Kean and Smith (2006a,b) methodology effectively averages the extracted roughness metrics at the reach scale, where a 'reach' is not clearly defined, but encompasses a set of self-similar features. As such the appropriateness of Kean and Smith's regularisation of irregular topographic features (equation 12) will depend upon the natural variation of topographic roughness in the averaging domain. It may be more appropriate to split large reaches into sections according to variations in the visible roughness elements (e.g. by failure types, geological controls etc.). Thirdly, the distance from the bank (zcrit) where the flow velocity value used for the outer region matching term should be measured is not defined by Kean and Smith (2006a,b). Darby et al., (2010) used a value of three times the bank height for the Mekong River where roughness element heights were $\sim 2 \mathrm{~m}$ on average. For the considerably smaller roughness elements of the Cecina, two and a half times the bank height is considered an adequate distance at which the influence of the bank forms has no impact on the flow. These distances are picked somewhat arbitrarily as the near-bank flow regions in natural channels are influenced directly by the planform morphology and form roughness of the banks. Experimental studies by Blanckaert et al. (2010; 2012) show that increasing bank roughness increases the distance to the outer boundary layer but equivalent studies have not yet been carried out in natural river channels. There is a need to quantify the influence of varying channel curvature and bank form roughness on the definition of $\mathrm{z}_{\text {crit }}$ in natural systems so that a more informed decision can be made as to the distance used and whether a reach averaged flow velocity at the specified distance is a suitably representative value. The implications are that such studies might reveal that it is not appropriate to use a temporally (and spatially) uniform value for the outer region flow velocity matching term, rather a term 
that evolves as banks erode and form roughness changes (see figure 10) might be more suitable.

\section{CONCLUSIONS}

This paper presents the first study into how the drag and skin friction components of the total boundary shear stress co-evolve with an eroding river bank. A series of eight high spatial resolution topographic bank surveys were undertaken between 2005 and 2011, using a combination of photogrammetry and TLS. DEMs were produced for each survey and used to construct a series of DoDs for each epoch of change. According to the method of Kean and Smith $(2006 a, b)$ Guassian curves fitted to the form roughness elements from five horizontal transects extracted from each survey were used to extract $H, \sigma$ and $\lambda$, the height, streamwise length and crest spacing of the individual elements. The residuals of the data points from the fitted Gaussian curves were used to directly estimate $z_{O S F}$. Regularisation of this variable set of features was undertaken according to the method of Kean and Smith (2006b) and these reach averaged values were used with an estimated value of $u_{\text {out }}$, based on the DELFT3D bankfull simulations of Rinaldi et al. (2008), to establish the relative magnitudes of $\tau_{D}$ and $\tau_{S F}$ for the Cecina at each survey.

Analysis of the distributions of the extracted roughness metrics revealed that they could be split into two distinct groups based on the spread of the data. In combination with the flow data, the DEMs and the DoDs, the metric distributions appear to show how periods of intense erosion and/or large flood events lead to an increase in form roughness. It is a wellestablished working hypothesis that form roughness increases the size of the near-bank internal boundary layer and decreases the potential for erosion (Smith and McLean, 1977; Chris and Caldwell, 1982; Parker et al., 2011), although this is yet to be observed in the field 
and remains the subject of future work. These features are subsequently 'trimmed' back and smoothed under successive flow conditions, diminishing the protective effect that they impart. Variations in the estimated values of $\tau_{D}$ and $\tau_{S F}$ for the Cecina support this selflimiting erosion mechanism and herein we propose a simple conceptual model (Figure 10) of how bank erosion and roughness co-evolve in this way.

Fundamentally this research shows that form roughness varies temporally as a function of erosion. Given the role of large form elements in modulating rates of bank retreat, future modelling efforts should consider the influence that variable form roughness might have on predictions in an attempt to at least acknowledge the considerable uncertainty it would introduce. The findings herein are empirical in nature, but we note that the identified trends are likely to apply across alluvial systems with a range of bank materials and flow conditions.

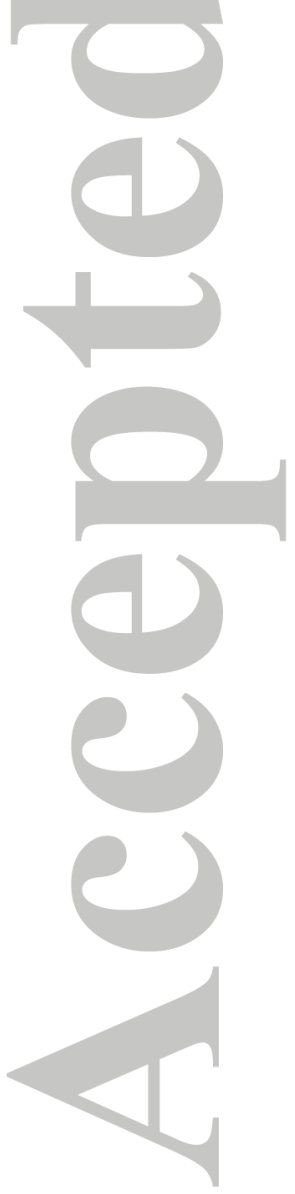

This article is protected by copyright. All rights reserved. 


\section{ACKNOWLEDGEMENTS}

Thanks to the Royal Society for Joint Project funding (SED and MR) which initiated the

Cecina River monitoring programme. Thanks also to the British Society for Geomorphology (BSG) for funding JL to undertake the 2011 TLS survey. Jason Kean (USGS) kindly provided a copy of the IDL script which was used to partition the boundary shear stress. Thanks to Beatrice Mengoni (Regione Toscana) for supplying the results from the DELFT3D simulations undertaken in Rinaldi et al. (2008). The KSGaussFit Matlab code is based on an earlier routine coded by Rosaria Scozzafava and Laura Nardi (University of Florence, Italy). Thanks to the Italian Hydrological Agency (Servizio Idrologico Regionale; SIR) for providing hydrological data and in particular to Dr. Giancarmine Trotta, Dr. A. Santucci, Dr. L. Pisani and Francesca Caparrini for undertaking MOBIDIC hydrological modelling. Thanks to Ivan Chiaverini for collaborating on processing of the photogrammetric surveys. Help was provided in the field by Laura Nardi, Simona Francalanci and University of Southampton undergraduates. Finally thanks to Jason Kean, Jim Pizzuto and the Associate Editor whose thoughtful comments improved an earlier version of this manuscript.

This article is protected by copyright. All rights reserved. 


\section{REFERENCES}

Alho P, Kukko A, Hyyppä H, Jaakola A. 2009. Application of boat-based laser scanning for river survey. Earth Surface Processes and Landforms 34: 1831-1838. DOI: 10.1002/esp. 1879

Arulanandan K, Gillogley E, Tully R. 1980. Development of a quantitative method to predict critical shear stress and rate of erosion of natural undisturbed cohesive soils. Report GL80-5, US Army Engineers, Waterways Experiment Station, Vicksburg, Mississippi.

Barker R, Dixon L, Hooke J. 1997. Use of terrestrial photogrammetry for monitoring and measuring bank erosion. Earth Surface Processes and Landforms 22: 1217-1227. DOI: 10.1002/(sici)1096-9837(199724)22:13<1217::aid-esp819>3.0.co;2-u

Bartholdy J, Billi P. 2002. Morphodynamics of a pseudomeandering gravel bar reach. Geomorphology 42: 293-310. DOI: 10.1016/S0169-555X(01)00092-7

Bennett SJ, Best JL. 1995. Mean flow and turbulence structure over fixed, two-dimensional dunes: implications for sediment transport and bedform stability. Sedimentology 42: 491513. DOI: 10.1111/j.1365-3091.1995.tb00386.x

Benvenuti M., Bonini M., Moratti G., Ricci M.\& Tanini C. 2008. Tectonic and climatic controls on historical landscape modifications: The avulsion of the lower Cecina River (Tuscany, central Italy). Geomorphology 100, 269-284. DOI: 10.1016/j.geomorph.2007.12.009

Blanckaert K, de Vriend HJ. 2010. Meander dynamics: A nonlinear model without curvature restrictions for flow in open-channel bends. Journal of Geophysical Research 115. DOI: 10.1029/2009jf001301

Blanckaert K, Duarte A, Chen Q, Schleiss AJ. 2012. Flow processes near smooth and rough (concave) outer banks in curved open channels. Journal of Geophysical Research 117. DOI: $10.1029 / 2012 j f 002414$

Brasington J, Langham J, Rumsby BT. 2003. Methodological sensitivity of morphometric estimates of coarse fluvial sediment transport. Geomorphology 53: 299-316. DOI: $10.1016 / \mathrm{s} 0169-555 \times 902) 00320-3$

Brasington J, Rumsby BT, McVey RA. 2000. Monitoring and modelling morphological change in a braided gravel-bed river using high resolution GPS-based survey. Earth Surface Processes and Landforms 25: 973-990. DOI: 10.1002/10969837(200008)25:9<973::aid-esp111>3.0.co;2-y 
Campo L, Caparrini F, Castelli F. 2006. Use of multi-platform, multi-temporal remotesensing data for calibration of a distributed hydrological model: an application in the Arno basin, Italy. Hydrological Processes 20: 2693-2712. DOI: 10.1002/hyp.6061

Carson MA, Kirkby MJ. 1972. Hillslope Form and Process. Cambridge University Press, Cambridge, 470pp.

Castelli F, Mancini M, Mazzanti B, Menduni G, Meneguzzo F, Niccolai M, Redini M, Todini E. 2001. Storm: a multi-agency approach to flood forecasting. In Mediterranean Storms, $3^{\text {rd }}$ Plinius Conference 2001, Deidda R, Mugnai A, Siccardi F (eds). CNR-GNDCI: 255262.

Chriss TM, Caldwell DR. 1982. Evidence for the influence of form drag on bottom boundary layer flow. Journal of Geophysical Research 87: 4148-4154. DOI: 10.1029/JC087iC06p04148

Couper PR, Maddock IP. 2001. Subaerial river bank erosion processes and their interaction with other bank erosion mechanisms on the River Arrow, Warwickshire, UK. Earth Surface Processes and Landforms 26: 631-646. DOI: 10.1002/esp.212

Darby SE, Rinaldi M, Dapporto S. 2007. Coupled simulations for fluvial erosion and mass wasting for cohesive river banks. Journal of Geophysical Research 112: F03022. DOI: 10.1029/2006JF000722

Darby SE, Thorne CR, Alonso CV, Borah DK, Diplas P, Julien P, Knight DK, Li L, Pizzuto JE, Quick M, Simon A, Stevens M, Watson C, Wang SSY. 1998. River width adjustment II: Modeling. Final Report of the ASCE Task Committee on Hydraulics, Bank Mechanics and Modeling of River Width Adjustment, Journal of Hydraulic Engineering 124: 903-917.

Darby SE, Trieu HQ, Carling PA, Sarkkula J, Koponen J, Kummu M, Conlan I, Leyland J. 2010. A physically-based model to predict hydraulic erosion of fine-grained river banks: The role of form roughness in limiting erosion. Journal of Geophysical Research 115: F04003. DOI: 10.1029/2010JF001708

Davies TRH, Sutherland AJ. 1980. Resistance to flow past deformable boundaries. Earth Surface Processes 5: 175-179. DOI: 10.1002/esp.3760050207

Davies TRH, Sutherland AJ. 1983. Extremal hypotheses for river behaviour. Water Resources Research 19: 141-148. DOI: 10.1029/WR019i001p00141

Eaton BC, Church M, Millar RG. 2004. Rational regime model of alluvial channel morphology and response. Earth Surface Processes Landforms 29: 511-529. DOI: 10.1002/esp.1062

This article is protected by copyright. All rights reserved. 
Goodson JM, Gurnell AM, Angold PG, Morrissey IP. 2002. Riparian seed banks along the lower River Dove UK. Geomorphology 47: 45-60. DOI: 10.1016/S0169$555 \mathrm{X}(02) 00140-\mathrm{X}$

Henriksen HJ, Troldborg L, Hojberg AJ, Refsgaard JC. 2008. Assessment of exploitable groundwater resources of Denmark by use of ensemble resource indicators and a numerical groundwater-surface water model. Journal of Hydrology 348: 224-240. DOI: 10.1016/j.jhydrol.2007.09.056

Hopson TM. 1999. The form drag of large natural vegetation along the banks of open channels, MSc thesis, University of Colorado, Boulder, Colorado, 114pp.

Julian JP, Torres R. 2006. Hydraulic erosion of cohesive riverbanks. Geomorphology 76: 193206. DOI: 10.1016/j.geomorph.2005.11.003

Kean JW, Smith JD. 2005. Generation and verification of theoretical rating curves in the Whitewater River basin, Kansas. Journal of Geophysical Research 110. DOI: 10.1029/2004jf000250

Kean JW, Smith JD. 2006a. Form drag in rivers due to small-scale natural topographic features: 1. Regular sequences. Journal of Geophysical Research 111: F04009. DOI: 10.1029/2006JF000467

Kean JW, Smith JD. 2006b. Form drag in rivers due to small-scale natural topographic features: 2. Irregular sequences. Journal of Geophysical Research 111: F04010, DOI: 10.1029/2006JF000490

Lawler DM. 1992. Process dominance in bank erosion systems. In: Carling PA, Petts GE. (Eds), Lowland Floodplain Rivers: Geomorphological Perspectives, John Wiley and Sons, Chichester, 117-143.

Lawler DM. 1993. The measurement of river bank erosion and lateral channel change: a review. Earth Surface Processes and Landforms 18: 777-821. DOI: 10.1002/esp.3290180905

Lawler DM. 2004. The importance of high-resolution monitoring in erosion and deposition dynamics studies: examples from estuarine and fluvial systems. Geomorphology 64: 123.

Lawler DM. 2005. Defining the moment of erosion: the principle of Thermal Consonance Timing. Earth Surface Processes and Landforms 30: 1597-1615. DOI: 10.1016/j.geomorph.2004.04.005 
Luppi L, Rinaldi M, Teruggi L, Darby SE, Nardi L. 2009. Monitoring and numerical modelling of riverbank erosion processes: a case study along the Cecina River (central Italy). Earth Surface Processes and Landforms 34: 530-546. DOI: 10.1002/esp.1754

Mancini F. 1966. Carta dei suoli d'Italia. In Comitato per la Carta dei Suoli. Tipografia Coppini: Firenze, Italy.

Marron DC. 1992. Floodplain storage of mine tailings in the Belle Fourche River system: A sediment budget approach. Earth Surface Processes and Landforms 17: 675-685. DOI: 10.1002/esp.3290170704

McBride M, Hession WC, Rizzo DM, Thompson DM. 2007. The influence of riparian vegetation on near-bank turbulence: a flume experiment. Earth Surface Processes and Landforms 32: 2019-2037. DOI: 10.1002/esp.1513

McLean SR, Smith JD. 1986. A model for flow over two-dimensional bed forms. Journal of Hydraulic Engineering 112: 300-317. DOI: 10.1061/(ASCE)0733-9429(1986)112:4(300)

Milan DJ, Heritage GL, Hetherington D. 2007. Application of a 3D laser scanner in the assessment of erosion and deposition volumes and channel change in a proglacial river. Earth Surface Processes and Landforms 32: 1657-1674. DOI: 10.1002/esp.1592

Millar RG. 2000. Influence of bank vegetation on alluvial channel patterns. Water Resources Research 36: 1109-1118. DOI: 10.1029/1999WR900346

Mosselman E. 1998. Morphological modeling of rivers with erodible banks. Hydrological Processes 12: 1357-1370. DOI: 10.1002/(SICI)1099-1085(19980630)12:8<1357::AIDHYP619>3.3.CO;2-Z

Nardi L, Campo L, Rinaldi M. 2013. Quantification of riverbank erosion and application in risk analysis. Natural Hazards. DOI: 10.1007/s11069-013-0741-8.

Nash, JE and Sutcliffe, JV. 1970. River flow forecasting through conceptual models part I A discussion of principles, Journal of Hydrology 10: 282-290. DOI: 10.1016/00221694(70)90255-6

Nelson JM and Smith JD. 1989. Mechanics of flow over ripples and dunes. Journal of Geophysical Research 94: 8146-8152. DOI: 10.1029/JC094iC06p08146

O'Neal MA, Pizzuto JE. 2011. The rates and spatial patterns of annual riverbank erosion revealed through terrestrial laser-scanner surveys of the South River, Virginia. Earth Surface Processes and Landforms 36: 695-701. DOI: 10.1002/esp.2098

Parker G, Shimizu Y, Wilkerson GV, Eke EC, Abad JD, Lauer JW, Paola C, Dietrich WE, Voller VR. 2011. A new framework for modeling the migration of meandering rivers. Earth Surface Processes and Landforms 36: 70-86. DOI: 10.1002/esp.2113

This article is protected by copyright. All rights reserved. 
Partheniades E. 1965. Erosion and depostion of cohesive soils. Journal of the Hydraulics Division of the ASCE 91: 105-139.

Piégay H, Darby SE, Mosselman E, Surian N. 2005. A review of techniques available for delimiting the erodible river corridor: a sustainable approach to managing bank erosion. Rivers Research and Applications 21: 773-789. DOI:10.1002/rra.881.

Pizzuto J, O'Neal M, Stotts S. 2010. On the retreat of forested, cohesive riverbanks. Geomorphology 116: 341-352. DOI: 10.1016/j.geomorph.2009.11.008

Prosser IP, Hughes AO, Rutherfurd ID. 2000. Bank erosion of an incised upland channel by subaerial processes: Tasmania, Australia. Earth Surface Processes and Landforms 25 : 1085-1101. DOI: 10.1002/1096-9837(200009)25:10<1085::AID-ESP118>3.3.CO;2-B

Pyle CJ, Richards KS, Chandler JH. 1997. Digital photogrammetric monitoring of river bank erosion. The Photogrammetric Record 15: 753-764. DOI: 10.1111/0031-868X.00083

Reneau SL, Drakos PG, Katzman D, Malmon DV, McDonald EV, Ryti RT. 2004. Geomorphic controls on contaminant distribution along an ephemeral stream. Earth Surface Processes and Landforms 29: 1209-1223. DOI: 10.1002/esp.1085

Resop JP, Hession WC. 2010. Terrestrial laser scanning for monitoring streambank retreat: a comparison with traditional surveying techniques. Journal of Hydraulic Engineering 136: 794-798. DOI: 10.1061/(ASCE)HY.1943-7900.0000233

Rinaldi M, Casagli N, Dapporto S, Gargini A. 2004. Monitoring and modelling of pore water pressure changes and riverbank stability during flow events. Earth Surface Processes and Landforms 29(2): 237-254. DOI: 10.1002/esp.1042

Rinaldi M, Luppi L, Mengoni B, Darby SE, Mosselman E. 2008. Numerical simulation of hydrodynamics and bank erosion in a river bend. Water Resources Research 44. DOI: 10.1029/2008WR007008

Rinaldi M, Darby SE. 2008. Modelling river-bank-erosion processes and mass failure mechanisms: progress towards fully coupled simulations. In: Habersack H, Piégay H, Rinaldi M (eds), Gravel-Bed Rivers 6 - From Process Understanding to River Restoration, Series Developments in Earth Surface Processes, 11, Elsevier, Netherlands, 213-239.

Schlichting H. 1979. Boundary-Layer Theory, McGraw-Hill, New York, 817pp.

Simon A, Collison AJ. 2002. Quantifying the mechanical and hydrological effects of vegetation on streambank stability. Earth Surface Processes and Landforms 27: 527-546. DOI: $10.1002 /$ esp. 325 
Simon A, Curini A, Darby SE, Langendoen EJ. 2000. Bank and near-bank processes in an incised channel. Geomorphology 35: 193-217. DOI: 10.1016/S0169-555X(00)00036-2

Smith JD, McLean SR. 1977. Spatially averaged flow over a wavy surface. Journal of Geophysical Research 82: 1735-1746. DOI: 10.1029/JC082i012p01735

Teruggi LB, Rinaldi M. 2009. Analysis of planimetric channel changes along the Cecina River (central Italy). In: International Proceedings of 27th IAS Meeting of Sedimentology, Medimond, Bologna, Italy, 27-30. ISBN 978-88-7587-555-8.

Teruggi LB, Rinaldi M, Chiaverini I, Ostuni D. 2011. Application of terrestrial photogrammetry to the measurement of a riverbank retreat. Italian Journal of Engineering Geology and Environment. Special Issue 2011: 115-122. DOI: 10.4408/IJEGE.2011-01.S09.

Thorne CR. 1982. Processes and mechanisms of river bank erosion. In: Hey RD, Bathurst JC, Thorne CR. (Eds), Gravel-bed Rivers, John Wiley and Sons, Chichester, 227-271.

Thorne CR, Lewin J. 1979. Bank processes, bed-material movement and planform development in a meandering river. In: Rhodes DD, Williams GP. (Eds) Adjustment of the Fluvial System, Kendall Hunt, 117-137.

Thorne SD, Furbish DJ. 1995. Influences of coarse bank roughness on flow within a sharply curved river bend. Geomorphology 12: 241-257. DOI: 10.1016/0169-555X(95)00007-R

Tolhurst TJ, Black KS, Shayler SA, Mather S, Black I, Baker K, Paterson DM. 1999. Measuring the in situ erosion shear stress of intertidal sediments with the Cohesive Strength Meter (CSM). Estuarine Coastal and Shelf Science 49: 281-294. DOI: 10.1006/ecss. 1999.0512

Wheaton JM, Brasington J, Darby SE, Sear DA, 2010. Accounting for uncertainty in DEMs from repeat topographic surveys: improved sediment budgets. Earth Surface Processes and Landforms 35: 136-156. DOI: 10.1002/esp.1886

Wheaton JM, Brasington J, Darby SE, Kasprak A, Sear DA, Vericat D. 2013. Morphodynamic signatures of braiding mechanisms as expressed through change in sediment storage in a gravel-bed river. Journal of Geophysical Research. DOI: 10.1002/jgrf.20060

WL Delft Hydraulics. 2006. Delft3D-FLOW: Simulation of Multidimensional Hydrodynamic Flows and Transport Phenomena, Including Sediments, User Manual. WL Delft Hydraulics: Delft.

Wood J. 1996. Scale-based characterization of digital elevation models. In: Parker D. (Ed.), Innovations in GIS 3. Taylor and Francis, London, pp. 163-175. 
Table 1. Overview of bank topographic surveys employed in this research and key hydrological events within each epoch of bank erosion. Survey methods: PHOT $=$ photogrammetry and TLS = terrestrial laser scanner

\begin{tabular}{|c|c|c|c|c|c|}
\hline $\begin{array}{l}\text { Survey Date } \\
\text { ID }\end{array}$ & $\begin{array}{l}\text { Survey } \\
\text { Method }\end{array}$ & $\begin{array}{c}\text { Mean Point } \\
\text { Density } \\
\left(N, \mathbf{m}^{2}\right) \\
\end{array}$ & $\begin{array}{l}\text { Mean Point } \\
\text { Spacing } \\
(\mathrm{m})\end{array}$ & $\begin{array}{c}\text { Bank } \\
\text { Erosion } \\
\text { Epoch } \\
\end{array}$ & $\begin{array}{c}\text { Peak Flow } \\
\left(Q_{\text {peak }}, \mathrm{m}^{3} / \mathrm{s}\right)\end{array}$ \\
\hline $02 / 02 / 2005$ & PHOT & 2066 & 0.021 & & \\
\hline 08/08/2005 & PHOT & 730 & 0.037 & $\begin{array}{l}\text { Feb.- Aug. } \\
2005\end{array}$ & 73 \\
\hline $11 / 01 / 2006$ & PHOT & 3086 & 0.018 & $\begin{array}{c}\text { Aug. } 2005- \\
\text { Jan. } 2006\end{array}$ & 774 \\
\hline 28/06/2006 & PHOT & 400 & 0.050 & $\begin{array}{l}\text { Jan. - Jun. } \\
2006\end{array}$ & 93 \\
\hline 20/02/2007 & PHOT & 816 & 0.035 & $\begin{array}{l}\text { Jun. } 2006- \\
\text { Feb. } 2007\end{array}$ & 607 \\
\hline $13 / 09 / 2008$ & TLS & 250,000 & 0.002 & $\begin{array}{l}\text { Feb. } 2007- \\
\text { Sep. } 2008\end{array}$ & 227 \\
\hline 06/07/2010 & PHOT & 5923 & 0.013 & $\begin{array}{l}\text { Sep. } 2008- \\
\text { Jul.2010 }\end{array}$ & 393 \\
\hline S8 27/07/2011 & TLS & 444,440 & 0.0015 & $\begin{array}{l}\text { Jul. } 2010- \\
\text { Jul. } 2011\end{array}$ & 498 \\
\hline
\end{tabular}


Table 2. Overview of vertically aggregated (through the five bank units BU1 - BU5, shown in figures 1 and 6) roughness metrics and Gaussian fits for each survey. The temporally aggregated statistics for each of the five bank units are also shown (BU1 - BU5). Note that the regularised metric values are reported using the products of Equation (11). The total roughness height, $z_{o T}$, is estimated from the Kean and Smith (2006a) routine.

\begin{tabular}{|c|c|c|c|c|c|c|c|}
\hline $\begin{array}{l}\text { Survey } \\
\text { ID }\end{array}$ & $\begin{array}{l}\text { No. Fitted } \\
\text { Bumps }\end{array}$ & $\begin{array}{c}\mathbf{R}^{2} \text { Gaussian } \\
\text { Fit }\end{array}$ & $\begin{array}{l}\lambda_{\text {reg }} \\
(\mathbf{m})\end{array}$ & $\begin{array}{l}H_{\text {reg }} \\
(\mathbf{m})\end{array}$ & $\begin{array}{l}\sigma_{\text {reg }} \\
(\mathbf{m})\end{array}$ & $\begin{array}{l}z_{O S F} \\
(\mathbf{m})\end{array}$ & $\begin{array}{l}z_{o T} \\
(\mathbf{m})\end{array}$ \\
\hline S1 & 410 & 0.83 & 0.87 & 0.145 & 0.237 & 0.00096 & 0.01 \\
\hline $\mathrm{S} 2$ & 742 & 0.72 & 0.88 & 0.146 & 0.236 & 0.00147 & 0.04 \\
\hline S3 & 472 & 0.60 & 0.87 & 0.145 & 0.237 & 0.00235 & 0.043 \\
\hline $\mathrm{S}$ & 323 & 0.86 & 0.77 & 0.128 & 0.305 & 0.00075 & 0.02 \\
\hline & 503 & 0.71 & 1.23 & 0.206 & 0.373 & 0.00215 & 0.118 \\
\hline S6 & 727 & 0.64 & 0.64 & 0.107 & 0.286 & 0.00206 & 0.004 \\
\hline S7 & 376 & 0.81 & 0.79 & 0.131 & 0.215 & 0.00066 & 0.015 \\
\hline S\& & 528 & 0.61 & 0.69 & 0.114 & 0.432 & 0.00238 & 0.003 \\
\hline BU1 & 1184 & 0.68 & 0.75 & 0.125 & 0.221 & 0.00136 & 0.013 \\
\hline BU2 & 972 & 0.77 & 0.93 & 0.156 & 0.261 & 0.00153 & 0.017 \\
\hline BU3 & 660 & 0.83 & 1.12 & 0.187 & 0.344 & 0.00211 & 0.018 \\
\hline BU4 & 639 & 0.75 & 0.83 & 0.138 & 0.418 & 0.00204 & 0.005 \\
\hline BU5 & 616 & 0.81 & 0.99 & 0.165 & 0.382 & 0.00184 & 0.011 \\
\hline
\end{tabular}



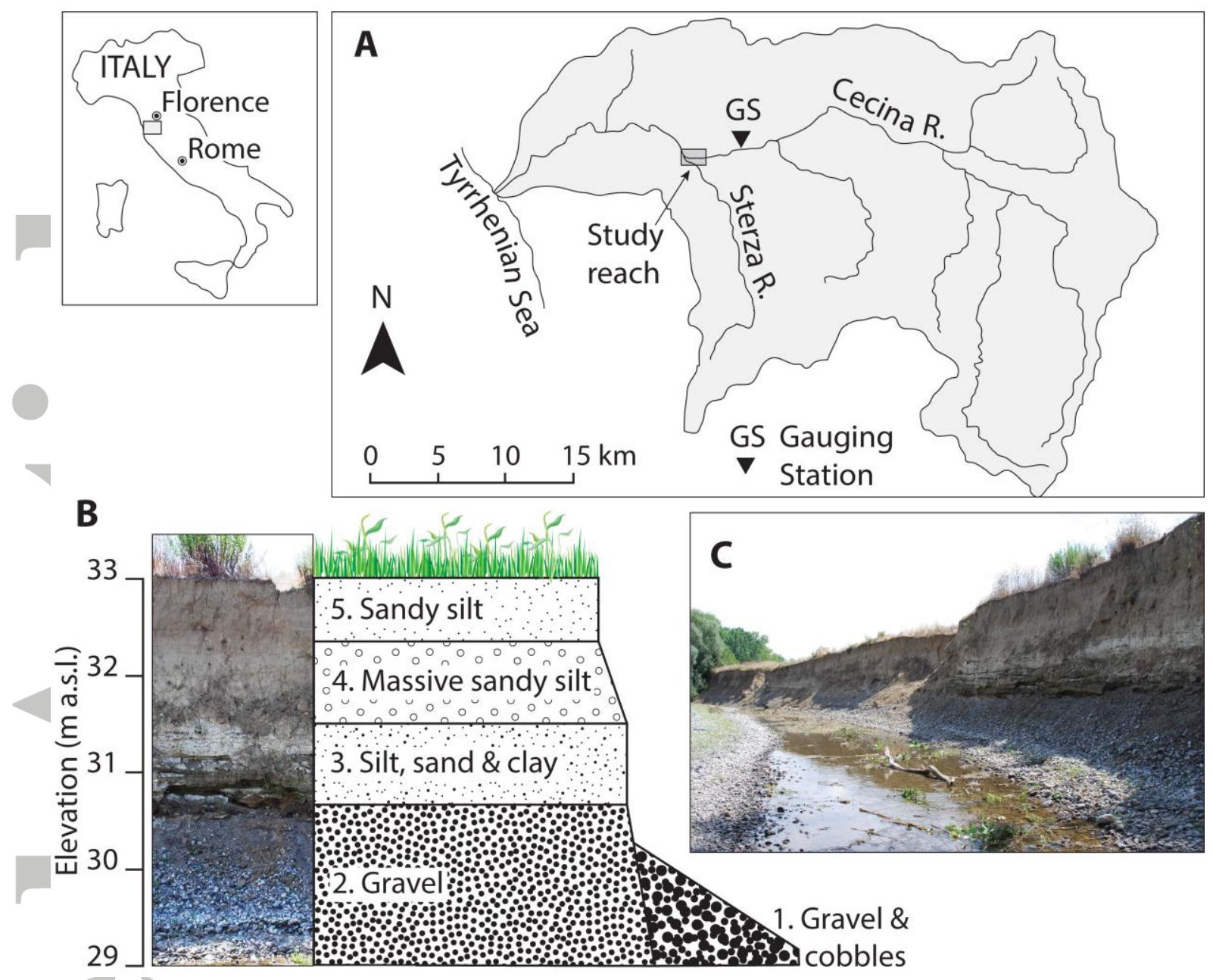

Figure 1. Location of the Cecina River study site: (a) Cecina basin and location of the study reach (GS: gauging station). (b) River bank stratigraphy: 1, loose gravel and cobbles; 2, gravel $(D 50=13 \mathrm{~mm}$; thickness ranging from 185 to $225 \mathrm{~cm}) ; 3$, silt, sand and clay (heterogeneous layer composed of alternating lenses of sand with $D 50=0.2 \mathrm{~mm}$, sandy silt levels with $D 50=0.01 \mathrm{~mm}$, and clayey silt horizons; total thickness ranging from 80 to 120 $\mathrm{cm}) ; 4$, massive sandy silt $(D 50=0.05 \mathrm{~mm}$; thickness ranging from 85 to $165 \mathrm{~cm}) ; 5$, sandy silt $(D 50=0.05 \mathrm{~mm}$, thickness ranging from 110 to $155 \mathrm{~cm})$. (c) ground-based photograph of the eroding bank that is the focus of this study. Figure 1 is modified from Luppi et al. (2009, Figure 1). 


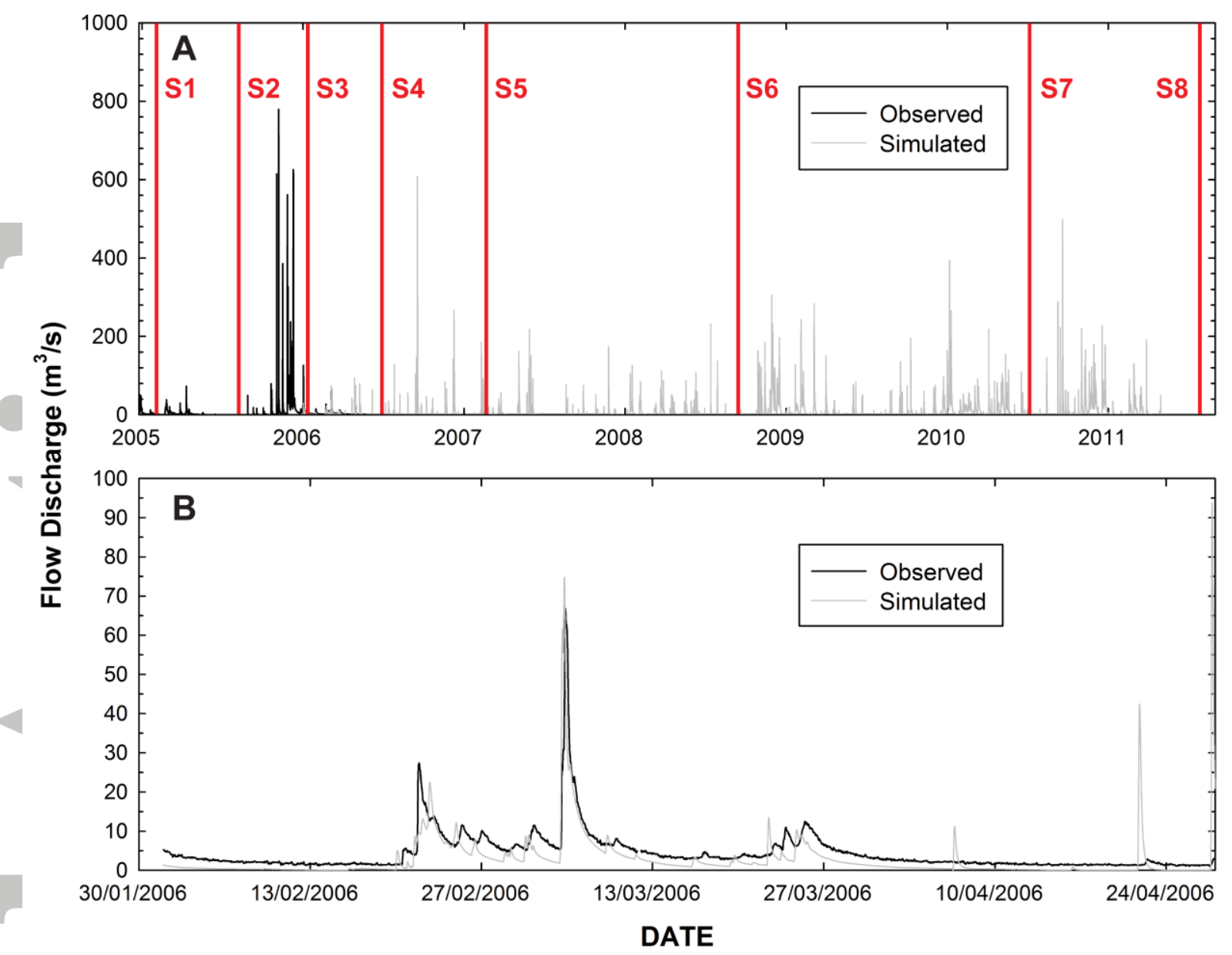

Figure 2. Simulated (May 2006 - September 2011) and observed (January 2005 - August 2006) time series of flow discharge at the Ponte di Monterufoli gauging station using the MOBIDIC distributed hydrological model developed for the Arno River Basin Authority (Castelli et al., 2001; Campo et al., 2006). Comparisons of the simulated and observed flows yield a Nash-Sutcliffe coefficient (Nash and Sutcliffe, 1970) of 0.737 and root mean square error (RMSE) of $3.6 \mathrm{~m}^{3} / \mathrm{s}$. Also shown are the dates of the bank morphological surveys, denoted by the red lines and a survey number.

This article is protected by copyright. All rights reserved. 


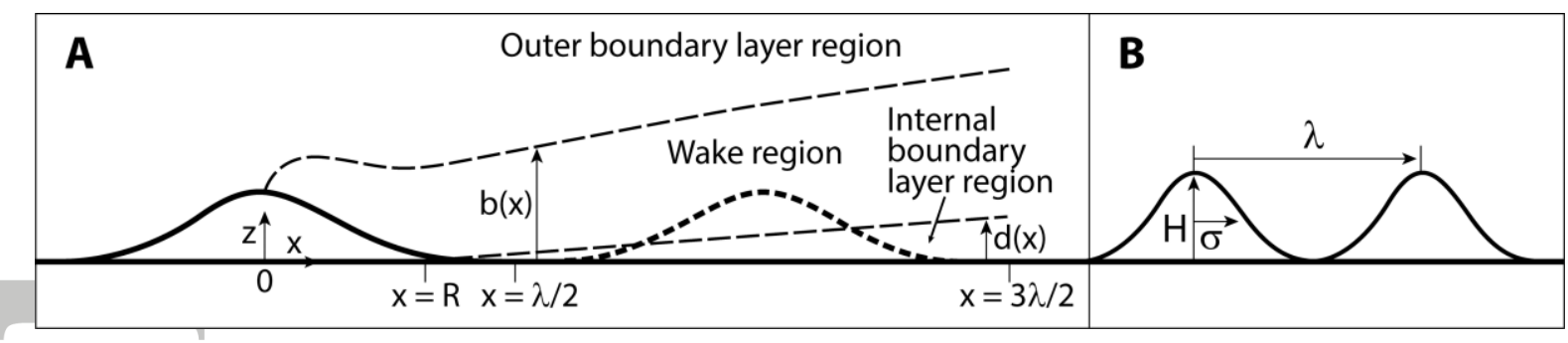

Figure 3. (a) Overview of the Gaussian-shaped plan view geometry of the modelled bank topographic roughness elements showing the internal boundary layer, wake, and outer regions of the flow (flow direction is left to right). The thick dashed line of the downstream element denotes that it is removed from the flow, with the $u_{\text {ref }}^{2}$ for this element being the average squared velocity over this area. The unit "cell" from $\lambda / 2$ to $3 \lambda / 2$ is the length over which the stresses are averaged. (b) The statistics required to characterise the topographic elements based on the fitted Gaussian distributions; $H$, the height of the element, $\sigma$, the streamwise length of the element and $\lambda$, the spacing between the crests of the elements. Figure 3 (a) is reproduced from Kean and Smith (2006a, Figure 2).
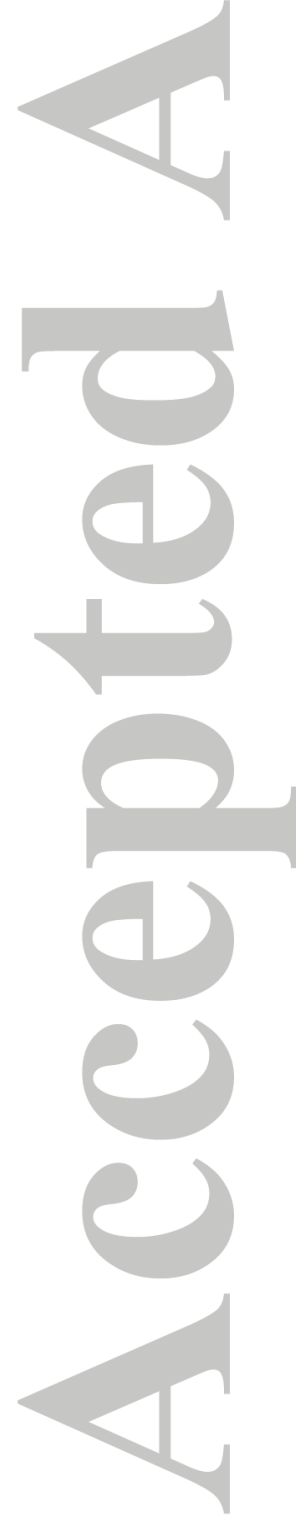

This article is protected by copyright. All rights reserved. 


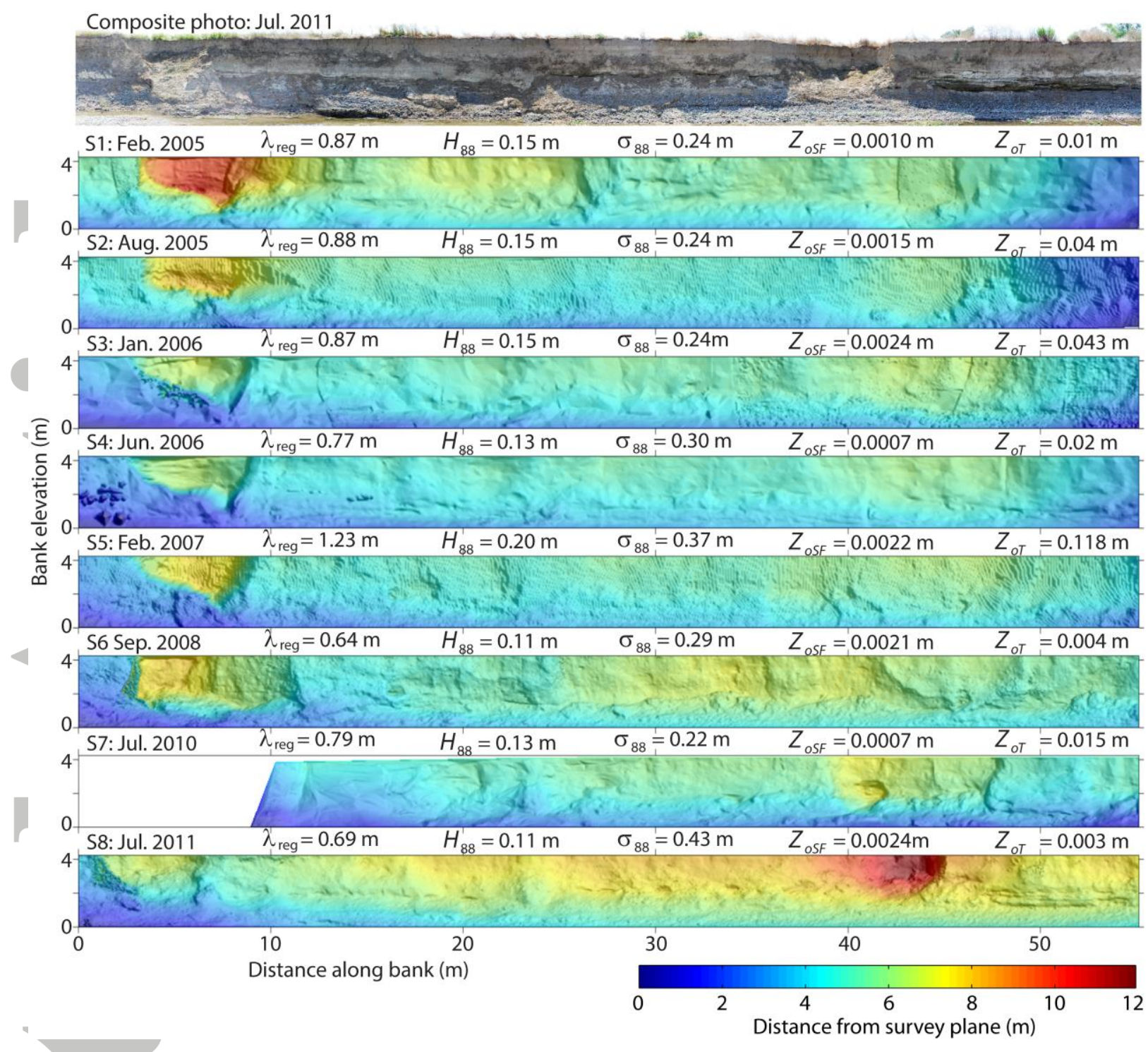

Figure 4. Digital Elevation Models (DEMs) coloured by distance from a standardised survey plane of each of the surveys used in the study. Also shown above each profile are the regularised values (see equation 12) for $\lambda, H$ and $\sigma$, the mean $z_{o S F}$ value and the $z_{o T}$ value; these are used for subsequent analysis using the Kean and Smith $(2006 a, b)$ method. The composite bank photo is constructed from seven high resolution photos merged together using Adobe Photoshop CS5.

This article is protected by copyright. All rights reserved. 


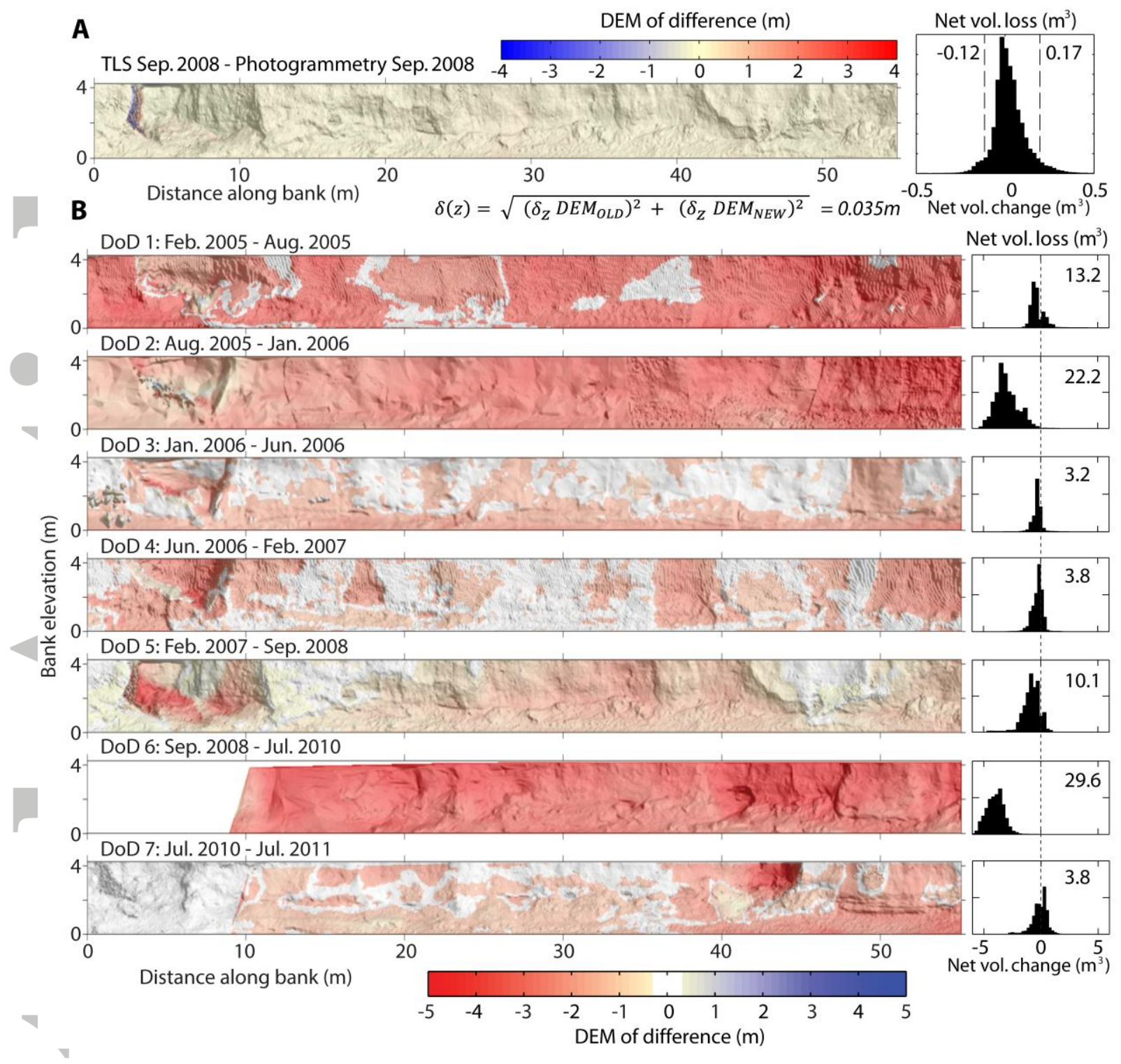

Figure 5. a) Calculation of the minimum level of detection $\left(L o D_{\min }\right)$ for the photogrammetric data which is used in the generation of $b$ ) the DEMs of Difference (DoDs) for each epoch of change.

This article is protected by copyright. All rights reserved. 
A
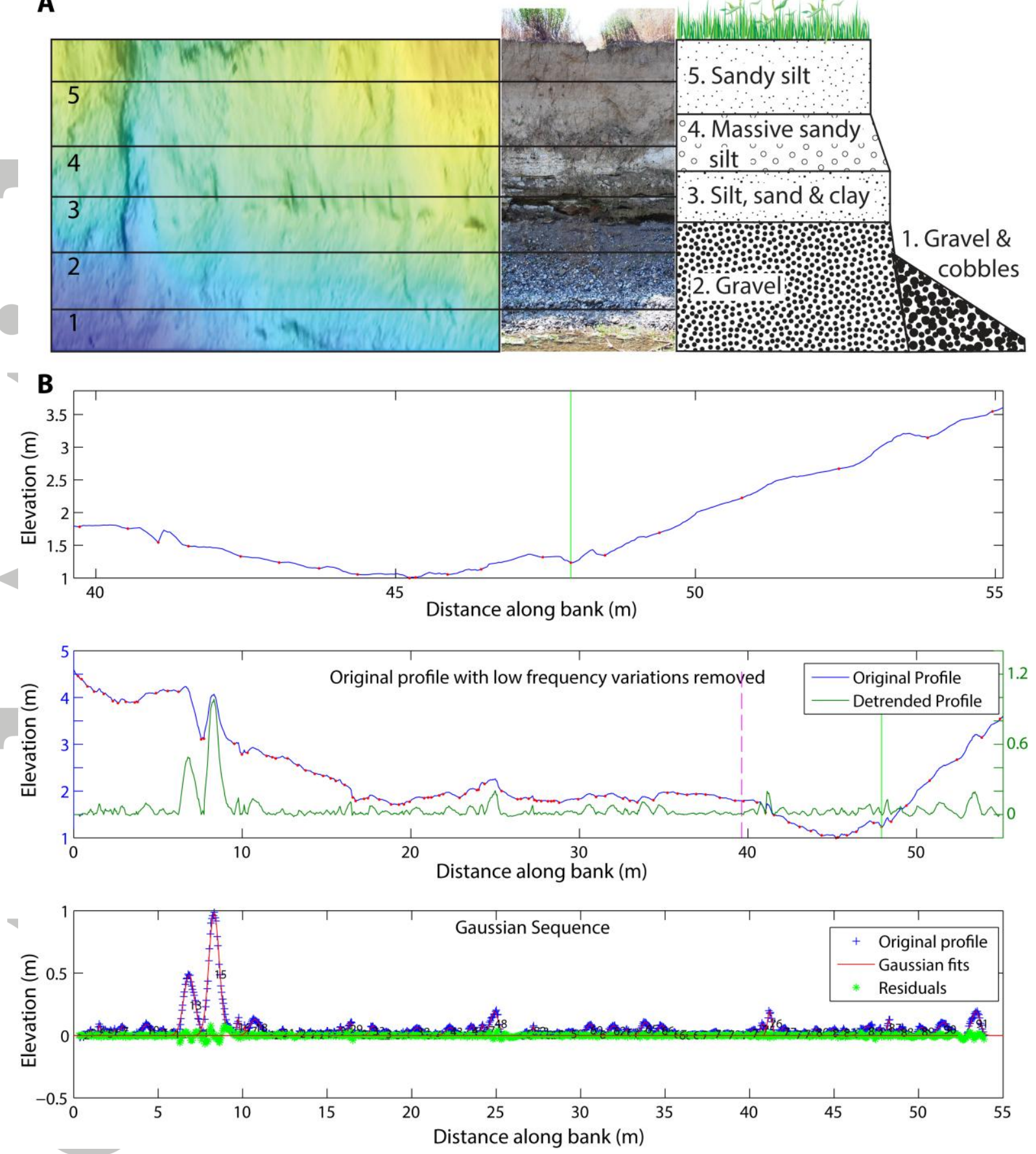

Figure 6. Extraction of Kean and Smith (2006a,b) metrics using the KSGaussFit MATLAB code which is available for download at: http://www.leyland.org.uk/downloads.html. (a) Profiles are extracted centrally from the five identified geological units of the Cecina River bank for each survey. b) Each profile is then analysed using Matlab codes (see text for detail) which allow the user to define bank low points (top panel) which are used as a basis for detrending the profile (middle panel) and to which a series of Gaussian curves are fitted to best represent bank form roughness elements (bottom panel). Distributions of $H$, the height of the element, $\sigma$, the streamwise length of the element and $\lambda$, the spacing between the crests of the elements are produced for each transect. The residuals from the fitted Gaussian curves are used to estimate $z_{O S F}$. 


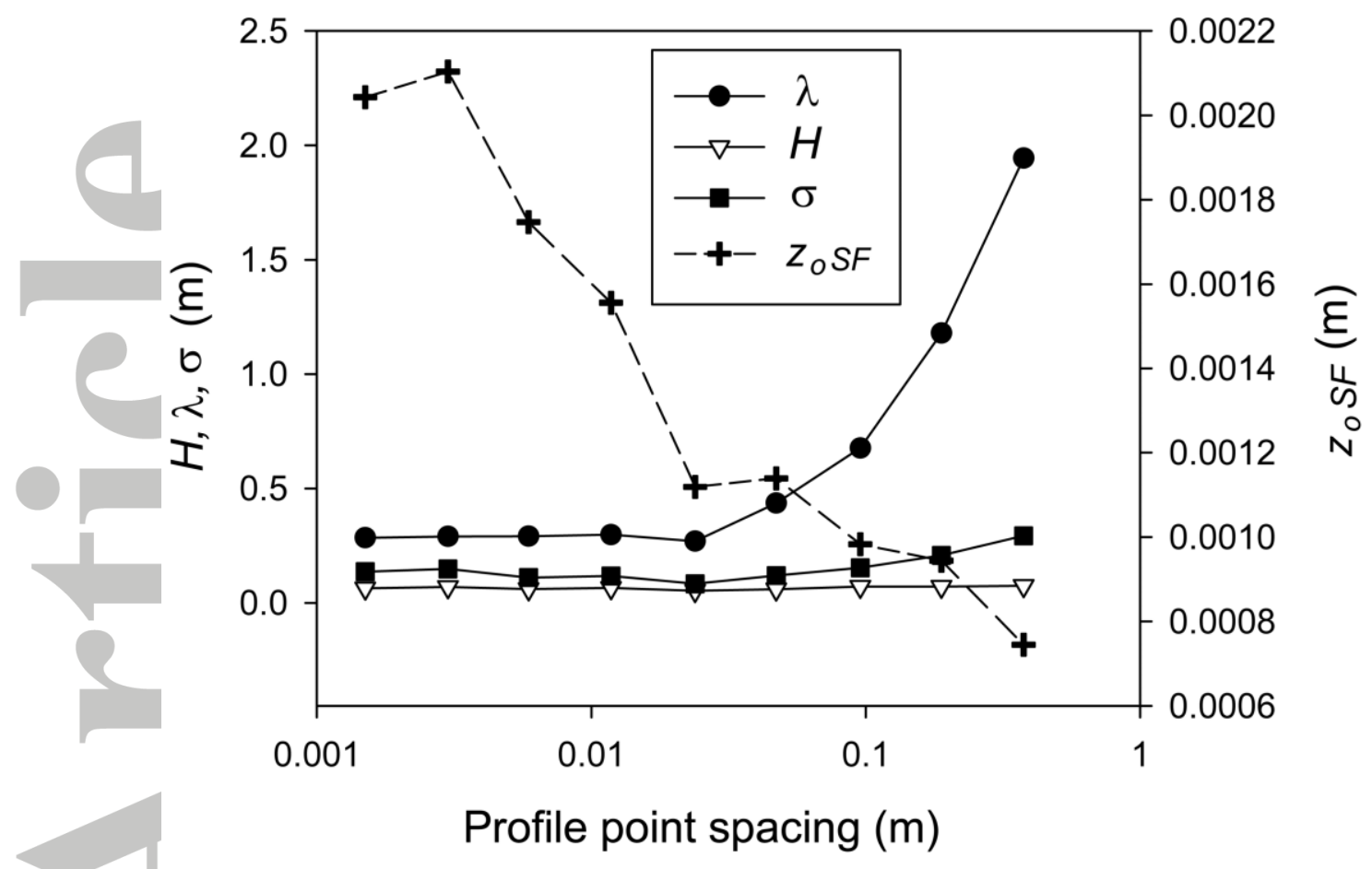

Figure 7. Variations in $H, \sigma, \lambda$ and $\mathrm{z}_{\mathrm{OSF}}$ as a function of the point spacing of the extracted profiles. The raw data for this scale dependence analysis was a profile from the 2011 TLS survey with a mean point spacing of $0.0015 \mathrm{~m}$. Point spacing was systematically degraded by resampling the original profile at twice the point spacing a total of ten times. 


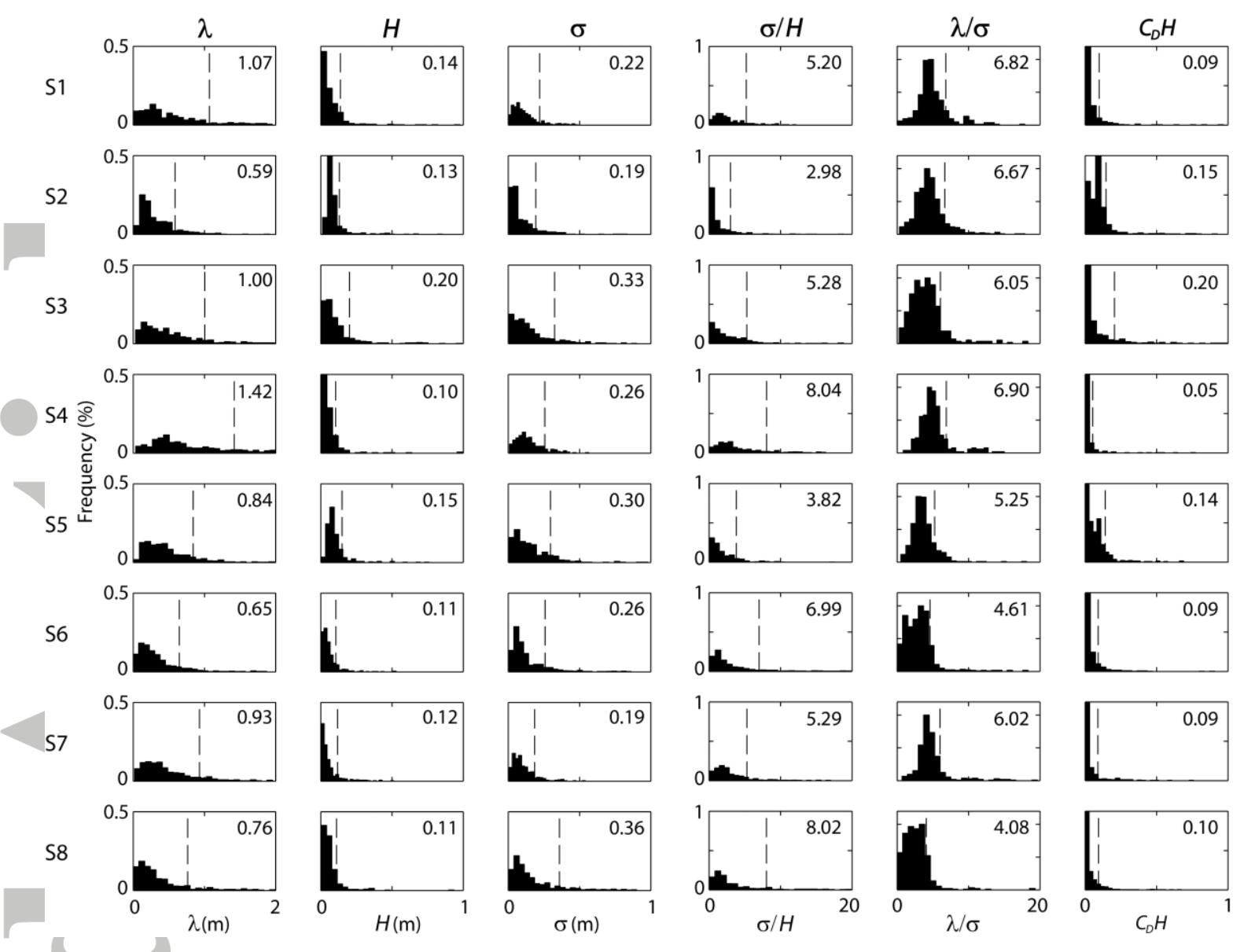

Figure 8. Histograms of $H, \sigma, \lambda$ and important combinations thereof as proposed by Kean and Smith (2006b), specifically $\sigma / H$ is the primary measure of the shape of the bank roughness element, $\lambda l \sigma$ is the ratio of the two streamwise length scales and the product $C_{D} H$ is a measure of the intensity of the wake produced by flow past the bank roughness element. The dashed lines and values shown on each plot are the $88^{\text {th }}$ percentile of the distribution, representing the regularised values used for $H$ and $\sigma$. Although $\lambda$ is regularised as a function of $H$, the $88^{\text {th }}$ percentile is included here from the irregular sequence for comparison. Similarly it is also shown on the combination plots, $\sigma / H, \lambda / \sigma$ and $C_{D} H$ as a means of comparison. All profiles at a given epoch are vertically aggregated to produce the distribution.

This article is protected by copyright. All rights reserved. 


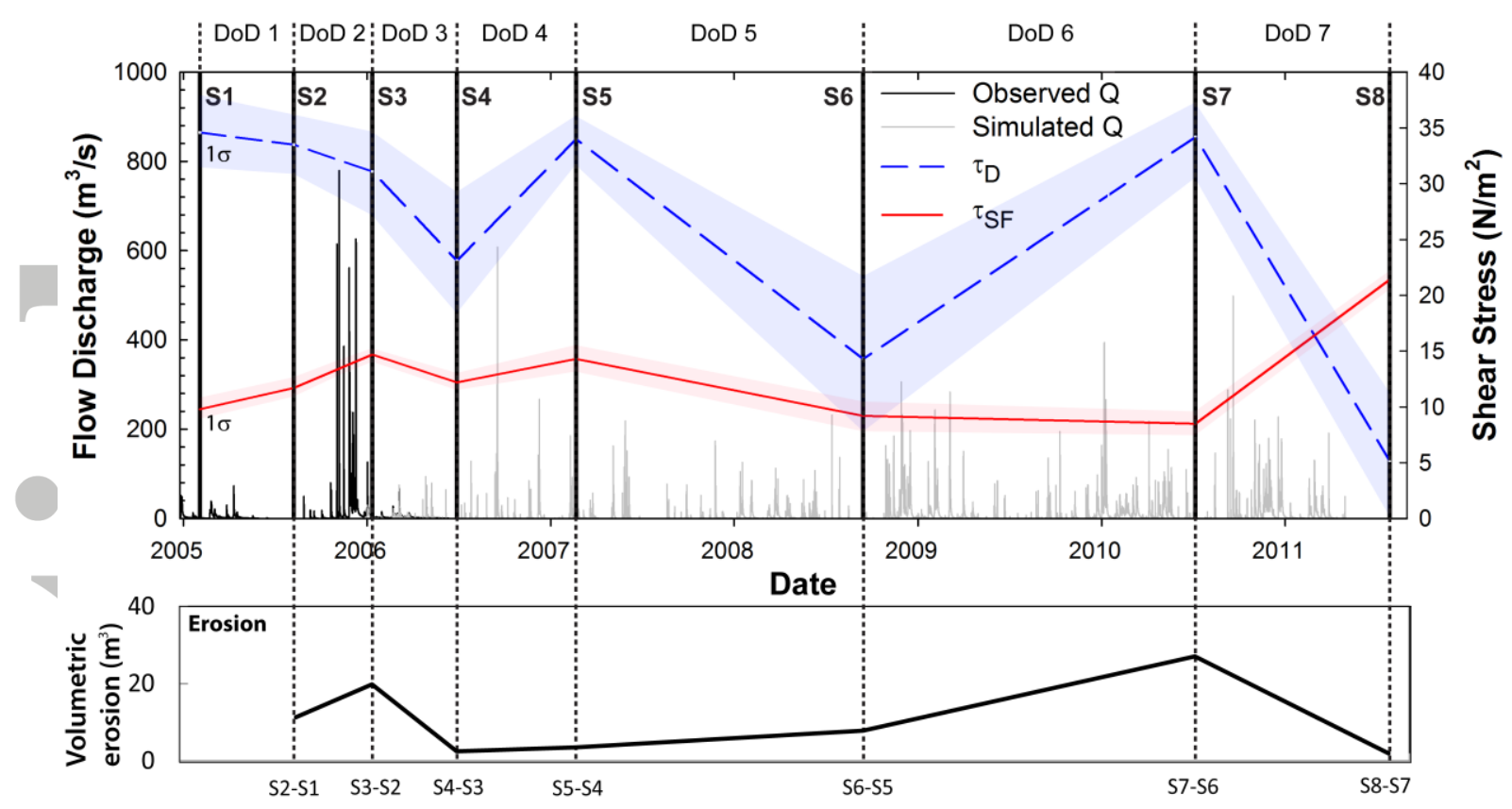

Figure 9. Variations in the mean relative magnitudes $\tau_{S F}$ and $\tau_{D}$, the skin and form frag components of the total boundary shear stress, the shading around the lines represents one standard deviation from the mean. Observed and simulated flow discharges for the Cecina River (see Figure 2 for details) are shown to aid analysis of the variations in $\tau_{S F}$ and $\tau_{D}$. The lower panel shows the total volumetric erosion between surveys. The survey dates and the epochs represented by the DEMs of Difference (DoDs) shown in Figure 9 are denoted for clarity. 


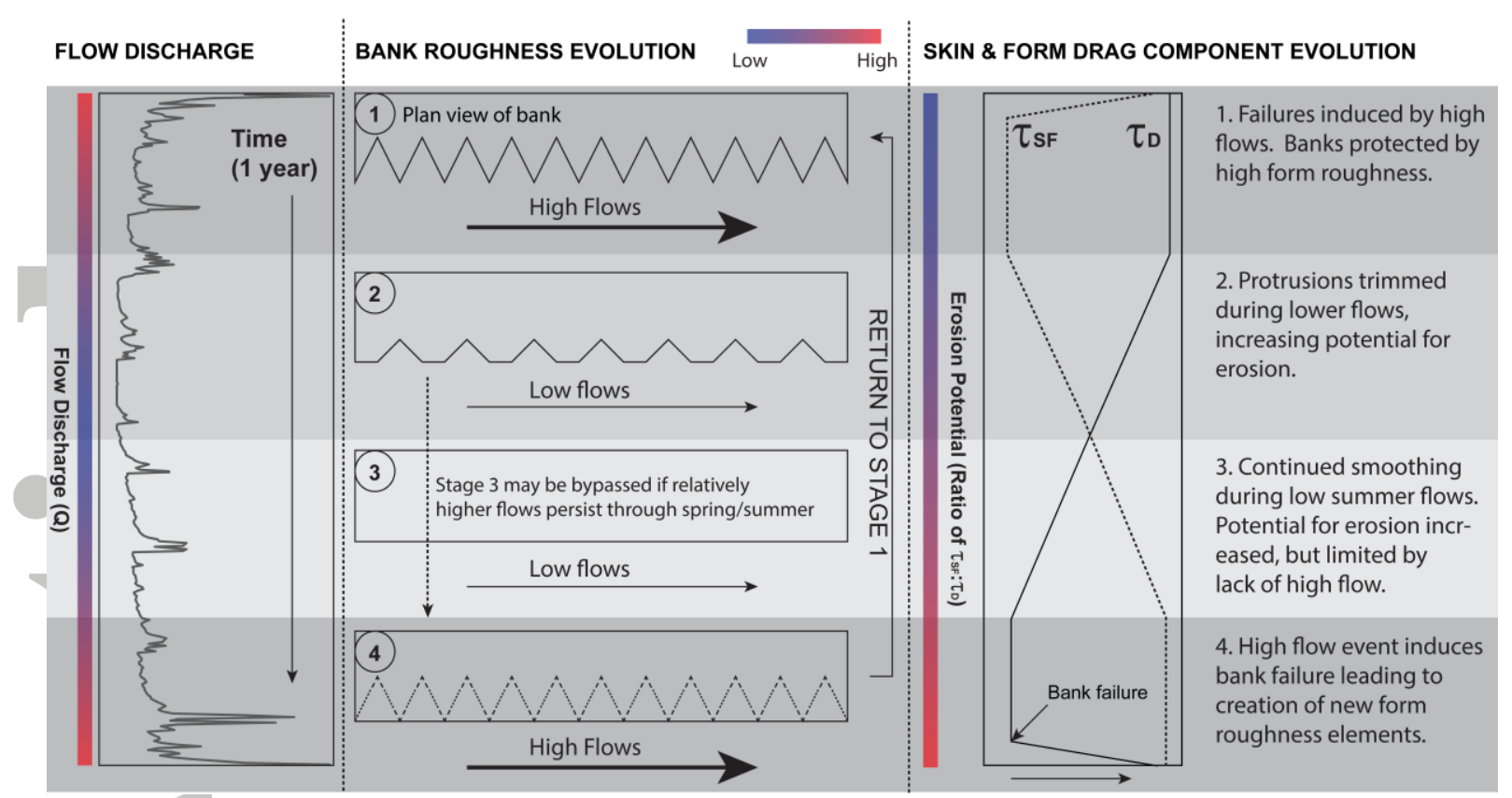

Figure 10. A conceptual model of how a river bank can self-limit erosion. The model shows co-evolving bank roughness and form and skin drag over the course of a hypothetical annual hydrograph. Stage 1 immediately proceeds a bank failure event, building up through the stages to the moment immediately preceding the next large scale failure event (stage 4). See text for a full description of each stage.

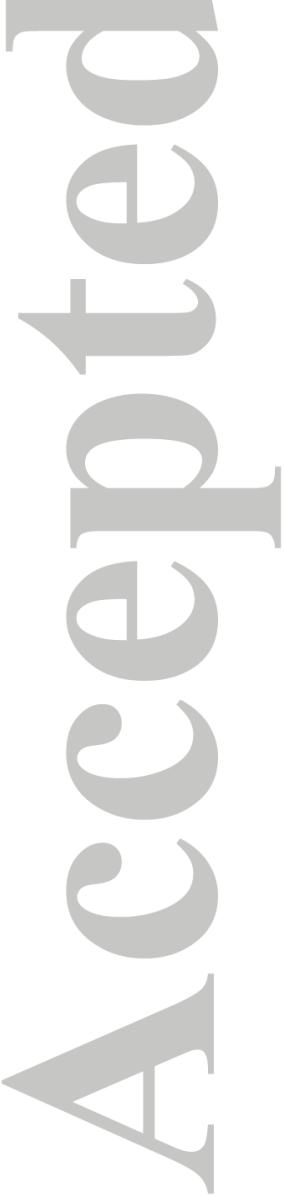

This article is protected by copyright. All rights reserved. 